\title{
Modelling Stock Returns in Africa's \\ Emerging Equity Markets
}

Paul Alagidede

Theodore Panagiotidis

Stirling Economics Discussion Paper 2009-04

January 2009

Online at http://www.economics.stir.ac.uk 


\title{
Modelling Stock Returns in Africa's Emerging Equity Markets
}

\author{
Paul Alagidede* and Theodore Panagiotidis\# \\ "Department of Economics, University of Stirling, Stirling, FK9 4LA, UK \\ paul.alagidede@stir.ac.uk \\ \#Department of Economics, University of Macedonia, 54006 Thessaloniki, \\ Greece, tpanag@uom.gr
}

January 2009

\begin{abstract}
We investigate the behaviour of stock returns in Africa's largest markets namely, Egypt, Kenya, Morocco, Nigeria, South Africa, Tunisia and Zimbabwe. The validity of the random walk hypothesis is examined and rejected by employing a battery of tests. Secondly we employ smooth transition and conditional volatility models to uncover the dynamics of the first two moments and examine weak from efficiency. The empirical stylized facts of volatility clustering, leptokurtosis and leverage effect are present in the African data.
\end{abstract}

Keywords: Stock Returns, Weak Form Efficiency, Asymmetric Volatility and African Stock Markets.

JEL: C22, C52, G10

Acknowledgements: We would like to thank David Chappell, Costas Milas and seminar participants in Loughborough University and London Metropolitan University for useful comments. 
But this is the age of globalisation, when investors feel free to boldly go where they had not gone before. After all, places that were previously regarded as exotic, from Bulgaria to Vietnam, are integrated into the global economy. Now it may be Africa's turn. Economist 29/6/2007.

\section{INTRODUCTION}

The Efficient Markets Hypothesis (EMH) holds that asset prices and returns are determined by the outcome of supply and demand in a competitive market, peopled by rational traders. These rational traders rapidly assimilate any information that is relevant to the determination of asset prices or returns, hence current prices (returns) fully reflect all available information (Fama, 1970). The notion that current prices fully reflect all available information implies that successive price changes (returns) are independent. Further, successive price changes are identically distributed. These two requirements constitute the cornerstone of the random walk model (Fama, 1970, pp 386-87).

At the same time there is growing evidence that stock returns exhibit stylized facts: first, the empirical distribution of stock returns appears to be excessively leptokurtic (Mandelbrot, 1963; Fama, 1965; Nelson, 1991). Second, short-term stock returns exhibit volatility clustering. These processes have been modelled successfully by ARCH-type models (see Bollerslev et al, 1992 for a review). Third, changes in stock prices tend to be inversely related to changes in volatility (Black, 1976; Christie, 1982; Bekaert and Wu, 2000). Most of the empirical work on these stylized facts has focused primarily on developed economies and a few emerging markets.

For investors seeking opportunities in developing countries however, little is known about the dynamic characteristics of stock returns (see Mecagni 
and Sourial, 1999; Appiah-Kusi and Menyah, 2003; Magnusson and Wydick, 2000, Smith and Jefferis, 2005 and Lim, 2007 who address some of these issues in African markets). Work on testing the weak form of market efficiency where nonlinearities are taken into account is limited and international evidence includes Brooks (2007), Lim et al (2008) and Panagiotidis (2005) and the references therein. An extensive review of the institutional characteristics of the African stock markets appears in Irving (2005) and in Yartey (2008). With increasing globalisation and world-wide integration of financial systems, interest has been rekindled in African stock markets largely on account of their low correlations with the rest of the world and the role they play in portfolio diversification. In 1994, African markets posted the biggest gains in U.S. dollar terms among all markets worldwide - Kenya (75 percent), Ghanaian stocks (70 percent), Zimbabwe (30 percent), Egypt (67 percent). In 1995, African stock exchanges gained about 40 percent, with the value of stocks on the Nigerian Stock Markets and Côte d'Ivoire's bourse registering over 100 percent increase in dollar terms. Average returns on African stocks in 2004 reached 44 percent. This compares favourably with a 30 percent return by the Morgan Stanley Capital International (MSCI) global index; 32 percent in Europe; 26 percent in the U.S. (Standard \& Poor's); and 36 percent in Japan (Nikkei) ${ }^{1}$. Additionally, African stock markets provide benefits of portfolio diversification as they tend to have zero or sometimes negative correlation with developed markets (see Harvey, 1995 for evidence on Nigeria and Zimbabwe). Recently, the Economist 
characterized Africa as globalization's final frontier for investors (29/7/07) and asking them to “Buy Africa” (19/2/2008).

This paper examines empirically the validity of the efficient markets hypothesis in African markets. Market efficiency is important because efficient stock prices allow agents to diversify their sources of investment capital and spread investment risk (see Caprio and Demirguc-Kunt, 1998). Also efficient stock prices and yields provide benchmarks against which the cost of capital for and returns on investment projects can be judged (Green et al, 2000 and also Green et al, 2005). Furthermore, since stock prices are forward looking, they provide a unique record of shifts in investors' views about the future prospects of companies as well as the economy (Green et al, 2005).

The main objective of this paper is to investigate whether the stylized facts observed in major advanced markets are present in African stock markets. We investigate the validity of the random walk hypothesis and employ smooth transition regressions (STR) and conditional volatility (GARCH) models to uncover the dynamics of the first two moments of the series. First, a linear random walk $(\mathrm{RW})$ is estimated for each market and the residuals are subjected to a battery of tests to investigate whether they are independently and identically distributed (iid). Models of the STR and GARCH family are then fitted. Our results show that the random walk is not adequate to capture the dynamics of the data. However, rejecting the random walk does not necessarily imply market inefficiency since market efficiency is a joint hypothesis (independent and identically distributed). We find evidence of volatility 
clustering in all countries (see also Brooks, 2007). In Kenya and Morocco, a change in stock prices is inversely related to volatility. Finally, we find a positive relationship between expected returns and risk in Tunisia, Kenya, Morocco and Zimbabwe. Thus, investors who venture into these markets are appropriately rewarded with higher returns for assuming greater risks.

The next section outlines the econometric methodology. Section three presents the data. The penultimate section is analysis of empirical results and five concludes.

\section{ECONOMETRIC METHODOLOGY}

Given the nature of the data, we avoid the temptation of imposing directly any specific data generating mechanism (infinite candidates). The methodology followed consists of the following steps:

i. The random walk is employed for the returns of each of the countries and test for iid through a battery of tests: McLeod and Li (1983) and Engle (1982) test for (G)ARCH effects; Brock et al (1991), Brock et al (1996) BDS tests for randomness; Hinich (1996) and Hinich and Patterson (1995) bicovariance test for third order non-linear dependence and Tsay (1986) for threshold effects in the data (for a detailed discussion of these tests see Patterson and Ashley 2000 and Ashley and Patterson 2006). All these tests share a common principle: once any linear serial dependence is removed from the data, any remaining dependence must be due to nonlinearities in the data generating mechanism. Additionally, we 
investigate whether the dynamics could be explained by a smooth transition model (STR) by employing the linearity test proposed by Luukkonen et al (1988).

ii. If both the RW and the STR fail to explain the behaviour of the data and there is strong evidence against the null hypothesis of iid, then we will proceed with employing GARCH-type of models.

The (logarithmic) random walk model is given by

$$
\log P_{t}=\log P_{t-1}+\varepsilon_{t}
$$

where $P_{t}$ is the price of a stock at time $t, P_{t-1}$ is the price of the stock in the immediately preceding period and $\varepsilon_{t}$ is a stochastic error term with $E\left[\varepsilon_{t}\right]=0, E\left[\varepsilon_{t}^{2}\right]=\sigma^{2}$ and $E\left[\varepsilon_{t} \varepsilon_{s}\right]=0 \forall s \neq t$. Thus $\varepsilon_{t}=\log P_{t}-\log P_{t-1}$, which being white noise, is unpredictable from previous price changes. To test the assumptions implied by the random walk, the following equation is estimated by least squares

$$
\Delta \log P_{t}=\mu+\varepsilon_{t}
$$

Under the RW $\log P_{t}$ should be $I(1)\left(\Rightarrow \Delta \log P_{t} \sim I(0)\right)$, the estimate of the constant $\mu$ should be insignificantly different from zero and the resultant residuals should be iid. This can however be positive if the stock market is growing. If the null of iid cannot be accepted, the implication is that the residuals contain some hidden, possibly non-linear structure.

At the same time, it is evident that volatility clustering, leptokurtosis and leverage effect are stylized features of financial data that linear models are 
unable to capture. The mean equation of stock prices (returns) could be described as

$$
\begin{aligned}
& \Delta \log P_{t}=\mu+\sum \phi_{i} \Delta \log P_{t-i}+\varepsilon_{t} \\
& \varepsilon_{t} \mid \Omega_{t-1} \sim \operatorname{NID}\left(0, h_{t}\right)
\end{aligned}
$$

The disturbance term $\varepsilon_{t}$ is conditionally heteroscedastic $\varepsilon_{t}=z_{t} \sqrt{h_{t}}$ where $z_{t}$ is iid with zero mean and unit variance. The conditional variance evolves according to the standard GARCH representation

$$
\begin{aligned}
h_{t}= & \omega+\sum_{i=1}^{q} \alpha_{i} \varepsilon^{2}{ }_{t-i}+\sum_{i=1}^{p} \beta_{i} h_{t-i} \\
& =\omega+\alpha(L) \varepsilon_{t}^{2}+\beta(L) h_{t}
\end{aligned}
$$

The $\phi_{i}$ parameter in (3) is included in the mean equation to take into account the autocorrelation induced by non-synchronous trading in the assets that make up a market index (see Lo and McKinlay, 1988, Scholes and Williams, 1977). The parameters in $\alpha(L)=\alpha_{1} L+\ldots \alpha_{q} L^{q}$ and $\beta(L)=\beta_{1} L+\ldots+\beta_{p} L^{p}$ are equivalent to an ARMA $(p, q)$ if all the roots of $1-\beta(L)$ lie outside the unit circle, and restrictions of $\omega>0, \alpha_{i}>0$ and $\beta_{i} \geq 0$ are imposed to ensure $h_{t} \geq 0$. Although, it is useful to specify a GARCH $(p, q)$, empirically, in most cases a lag structure of $p=q=1$ is adequate (see Bollerslev et al, 1992).

However many models of asset pricing relate expected returns to some measure of risk. The GARCH-in-Mean (GARCH-M) model of Engle et al (1987) 
can be used to explicitly parameterize the conditional expectation of asset returns as a function of volatility. To this end, (3) now becomes

$$
\Delta \log P_{t}=\mu+\sum \phi_{i} \Delta \log P_{t-i}+\delta h_{t}+\varepsilon_{t}
$$

Thus $\delta$ is interpreted as a risk premium so that a positive and significant $\delta$ indicates that return is positively related to volatility.

The notion of asymmetry has its origins in the work of Black (1976), French et al (1987), Nelson (1991) and Schwert (1990). A model that captures asymmetry is the exponential GARCH (EGARCH) model of Nelson (1991)

$$
\ln \left(h_{t}\right)=\omega+\alpha_{1} z_{t-1}+\gamma_{1}\left(\left|z_{t-1}\right|-E\left(\left|z_{t-1}\right|\right)\right)+\beta_{1} \ln \left(h_{t-1}\right)
$$

The natural $\log$ formulation of EGARCH ensures positive variances, thus dispensing with the need for parameter restrictions; also volatility at time $t$ depends on both the size and sign of the normalized errors. Given the properties of $z_{t}, g\left(z_{t}\right) \equiv \alpha_{1} z_{t}+\gamma_{1}\left(\left|z_{t}\right|-E\left(\left|z_{t}\right|\right)\right)$ has mean zero and is uncorrelated. Thus $g\left(z_{t}\right)$ is piecewise linear in $z_{t}$ and can be rewritten as

$$
g\left(z_{t}\right)=\left(\alpha_{1}+\gamma_{1}\right) z_{t} I\left(z_{t}>0\right)+\left(\alpha_{1}-\gamma_{1}\right) z_{t} I\left(z_{t}<0\right)-\gamma_{1} E\left(z_{t}\right)
$$

This implies that positive shocks will have an impact $\alpha_{1}+\gamma_{1}$ on $\ln \left(h_{t}\right)$, while for negative shocks, the impact is $\alpha_{1}-\gamma_{1}$. 


\section{DATA}

The data consists of daily closing prices of CASE 30 (Egypt), NSE 20 (Kenya), TUNINDEX (Tunisia) and MASI (Morocco), ZSE Industrials (Zimbabwe), JSE All Share (South Africa) and NSE All Share (Nigeria) (Source: DataStream). These countries represent the largest stock markets in Africa and account for over 90 percent of total capitalisation, and over 80 percent of domestic company listings. With the exception of a few restrictions in Zimbabwe, all the markets are opened to foreign investors. A summary of the key features is presented in table 1.

Table 1: Features of African Stock Markets

\begin{tabular}{|c|c|c|c|c|c|c|c|c|c|c|c|c|c|}
\hline & \multicolumn{2}{|c|}{$\begin{array}{l}\text { Number of } \\
\text { Companies }\end{array}$} & \multicolumn{2}{|c|}{$\begin{array}{c}\text { Turnover } \\
\text { Ratio }\end{array}$} & \multicolumn{2}{|c|}{$\begin{array}{c}\text { Capitalisation } \\
\text { (million\$) }\end{array}$} & \multirow{2}{*}{$\begin{array}{c}\text { Cap/GDP } \\
\text { Ratio } \\
\\
2004\end{array}$} & \multirow{2}{*}{$\begin{array}{c}\text { Share of } \\
\text { Emerging } \\
\text { Markets } \\
2004\end{array}$} & \multirow{2}{*}{$\begin{array}{c}\text { Dividend } \\
\text { Yield } \\
\\
2004\end{array}$} & \multicolumn{3}{|c|}{$\begin{array}{c}\text { Withholding taxes } \\
\text { (end of 2004) }\end{array}$} & \multirow[t]{2}{*}{ Restriction } \\
\hline & 1995 & 2004 & 1995 & 2004 & 1995 & 2004 & & & & interest & dividend & gains & \\
\hline Kenya & 56 & 47 & 2.8 & 8.2 & 1886 & 3891 & 24.2 & 3.2 & 4.9 & 15 & 10 & 0 & free \\
\hline Morocco & 44 & 52 & 45.9 & 9.1 & 2426 & 1677 & 50.1 & 0.5 & 2.7 & 10 & 10 & 35 & free \\
\hline Tunisia & 26 & 44 & 19.8 & 9.2 & 3927 & 2641 & 9.4 & 2.2 & 4.5 & 15 & 0 & 35 & free \\
\hline Zimbabwe & 64 & 79 & 7.6 & 9.2 & 2038 & 1941 & 41.3 & 0.1 & 4.1 & 10 & 20 & 0 & SR \\
\hline Nigeria & 181 & 207 & 0.8 & 13.7 & 2033 & 14464 & 20.1 & 0.3 & 3.7 & 10 & 10 & 10 & free \\
\hline Egypt & 746 & 792 & 10.9 & 17.3 & 8088 & 38515 & 48.9 & 0.8 & 1.5 & 5 & 0 & 40 & free \\
\hline S. Africa & 640 & 403 & 6.5 & 47.4 & 28052 & 455536 & 236 & 9.8 & 3.1 & 0 & 0 & 0 & free \\
\hline Brazil & 543 & 357 & 47.9 & 34.9 & 14636 & 330347 & 59.6 & 7.1 & 4.1 & 15 & 0 & 0 & free \\
\hline China & 323 & 1384 & 115. & 113.3 & 42055 & 639765 & 34.9 & 13.8 & 2 & 10 & 10 & 33 & $\mathrm{RF}$ \\
\hline India & 5398 & 4730 & 17.1 & 115.5 & 127199 & 387851 & - & 8.3 & 1.6 & 15 & 0 & 20 & SR \\
\hline Russia & 170 & 215 & 2.6 & 53 & 15883 & 267957 & 71.8 & 5.8 & 1.6 & 0 & 10 & 24 & free \\
\hline
\end{tabular}

Source: S\&P (2005) Global Stock Market Fact book. Capitalisation/GDP ratio obtained from World Development Indicators Database, April (2006). SR stands for Some Restrictions and RF for Relatively Free.

The dominance of South Africa and the relatively low market capitalisation and turnover is evident from table 1 (for an extensive review of individual markets see Irving, 2005)2. Table 2 reports the summary statistics of the daily return series together with the sample period ${ }^{3}$. These include the 
standard deviation (highest in Zimbabwe, lowest in Tunisia); skewness (Zimbabwe and Tunisia still being the two extremes) and excess kurtosis (highest in Kenya, lowest in South Africa). The Jarque-Bera statistic rejects normality, evidence similar to the finding in Brooks (2007) that look at the distribution of emerging markets returns. Non-normality could be induced in part by temporal dependencies in returns, especially second moment temporal dependence. The presence of such dependence is tested by the Ljung-Box statistics calculated for ten lags.

Table 2. Descriptive Statistics (Logarithmic Returns)

\begin{tabular}{|lccccccc|}
\hline & Egypt & Kenya & Morocco & Nigeria & S. Africa & Tunisia & Zimbabwe \\
\hline \hline & $03 / 04 / 2001$ & $03 / 04 / 2001$ & $03 / 04 / 2001$ & $6 / 30 / 1995$ & $04 / 01 / 2001$ & $1 / 02 / 1998$ & $1 / 01 / 1996$ \\
Sample & to & to & to & to & to & to & to \\
& $03 / 04 / 2006$ & $03 / 04 / 2006$ & $03 / 04 / 2006$ & $6 / 30 / 2006$ & $03 / 04 / 2006$ & $6 / 30 / 2006$ & $3 / 01 / 2001$ \\
Obs & 1306 & 1306 & 1306 & 2871 & 1368 & 2216 & 1566 \\
Mean $(\mu)$ & 0.00097 & 0.00062 & 0.00041 & 0.00089 & 0.00051 & 0.0003 & 0.00133 \\
St. Dev $(\sigma)$ & 0.0137 & 0.0107 & 0.00709 & 0.0085 & 0.0117 & 0.0047 & 0.0168 \\
Skewness $(S)$ & 0.566 & 0.1544 & 0.3197 & 0.1008 & 0.0479 & 0.885 & -1.23 \\
Kurtosis $(K)$ & 9.72 & 47.66 & 8.75796 & 8.083 & 5.1301 & 15.39 & 25.072 \\
JB & $2014.6^{* * *}$ & $98841.3^{* * *}$ & $1763.3^{* * *}$ & $2933.1^{* * *}$ & $225.8^{* * *}$ & $13662^{* * *}$ & $36862^{* * *}$ \\
\hline LB & $38.963^{* * *}$ & $48.812^{* * *}$ & $104.9^{* * *}$ & $810.6^{* * *}$ & $30.849^{* * *}$ & $204.42^{* * *}$ & $177.9^{* * *}$ \\
\hline \hline
\end{tabular}

*** Denotes statistical significance at $1 \%$ level; JB is the Jarque-Bera test for normality; LB is the Ljung-Box test statistic for autocorrelation (10 lags).

The hypothesis that all autocorrelations up to the $10^{\text {th }}$ lag are jointly zero is rejected. Possible reasons for autocorrelation in the returns are nonsynchronous trading (see Scholes and Williams, 1977; Fisher, 1966) and timevarying short term expected returns (Conrad and Kaul, 1988). 


\section{EMPIRICAL RESULTS AND DISCUSSIONS}

\subsection{The Random Walk Model}

The RW estimates (equation 2) are presented in table 3.

Table 3: Estimates of Random Walk Model

\begin{tabular}{|cccccccc|}
\hline \hline & Egypt & Kenya & Morocco & Nigeria & Tunisia & S.Africa & Zimbabwe \\
\hline \hline$\mu$ & $0.001018^{* *}$ & $0.000625^{* *}$ & 0.0000393 & $0.00088^{* * *}$ & $0.000226^{* *}$ & $0.000549^{*}$ & $0.001006^{* *}$ \\
& $(2.1577)$ & $(2.0034)$ & $(0.1809)$ & $(5.3704)$ & $(2.054)$ & $(1.7325)$ & $(2.2001)$ \\
LB & 25.19 & 44.6 & 98.59 & 736.1 & 192.75 & 20.38 & 151.7 \\
JB & 2014.6 & 98841 & 1763 & 2933 & 13662 & 225.8 & 3686 \\
$\mathrm{R}^{2}$ & 0.000 & 0.000 & 0.000 & 0.000 & 0.000 & 0.000 & 0.000 \\
\hline \hline
\end{tabular}

Notes: ${ }^{*}, * *$, and $* * *$ indicates significance at $10 \%, 5 \%$ and $1 \%$ levels respectively, $\mu$ is the constant, JB is the Jarque-Bera test for normality, and LB is the Ljung-Box statistic for serial correlation(10 lags). Test statistics are reported in parenthesis beneath the estimated coefficients.

The $t$-statistic of the estimated constant is below the critical value at the $10 \%$ significance level in Morocco, indicating that the mean of the series $\Delta \log P_{t}$ is insignificantly different from zero. For the rest of the countries the constant term is significant. Also the Ljung-Box test indicates there is correlation up to 10 lags. We, therefore, reject the random walk as an adequate characterisation of returns in our sample of African countries ${ }^{4}$. The next step is to subject the residuals of the model to a battery of tests.

Previous evidence on the random walk model in African markets has often yielded mixed results using serial correlation tests. Ekechi (1989) and Dickinson and Muragu (1994) find evidence consistent with the random walk in Nigeria and Kenya respectively, Olowe (1999) rejected the random walk in Nigeria. Magnussen and Wydick (2002) find that none of the African markets 
under consideration fulfils the iid condition for weak form efficiency. In order to examine further the iid properties of the data, we employ a battery of tests instead of a single procedure (for a review of the literature see Ashley and Patterson, 2006 and Panagiotidis, 2005). The summary of the results is displayed in table 4 (see also table 8 in the appendix for the details).

Table 4: Tests on the Randomness of the RW Residuals

\begin{tabular}{|c|c|c|c|c|c|c|c|}
\hline & Egypt & Kenya & Morocco & Nigeria & South Africa & Tunisia & Zimbabwe \\
\hline $\begin{array}{c}\text { McLeod-Li } \\
\text { (ARCH) }\end{array}$ & $x$ & $x$ & $x$ & $x$ & $x$ & $x$ & $x$ \\
\hline $\begin{array}{l}\text { Engle LM } \\
\text { (GARCH) }\end{array}$ & $x$ & $x$ & $x$ & $x$ & $x$ & $x$ & $x$ \\
\hline Tsay & & & & & & & \\
\hline & $x$ & $x$ & $x$ & $x$ & $x$ & $x$ & $x$ \\
\hline Bicovariance & $x$ & $x$ & $x$ & $x$ & $x$ & $x$ & $x$ \\
\hline BDS & $x$ & $x$ & $x$ & $x$ & $x$ & $x$ & $x$ \\
\hline
\end{tabular}

Note: $x$ indicates rejection of the null of $i i d$ at the $5 \%$ level in the residuals of the RW. See also table 8 in the appendix for the details

All the test statistics reject the null of iid for the residuals of the RW (all $p$-values are very close to zero in all countries). This indicates that the data generating mechanism (DGP) is non-linear ${ }^{5}$. The strong degree of dependence in the residuals of the random walk indicates the inadequacy of the model to explain the (more complex) behaviour of index returns. We can not exclude any form of non-linearity since all the tests provide us with $0 p$-values (for instance if the Engle test would reject we cannot exclude an ARCH DGP and if the Tsay test not reject, we can not argue for a TAR model). The presence of nonlinearities in the series could imply evidence of return predictability. Neftci (1991) demonstrates that technical trading rules require some form of nonlinearity in 
prices to be successful and Mills (1997) argues that the presence of nonlinearity is a necessary condition for trading rules to have potential predictive power.

\subsection{Smooth Transition Regression}

Another form of non-linearity could be captured by a STR (see van Dijk et al ,2002 for a review). Our methodology follows the following steps: i) Fit the best AR linear model, ii) test for linearity, iii) choose the type of STR model and iv) test the residuals of the best STR model for GARCH. The standard STR model is defined as:

$y_{t}=f \mathbb{\Psi}_{t}+q \mathbb{E}_{t} G\left(g, c, s_{t}\right)$

where $z_{t}=\left(w_{t}^{\mathbb{\Phi}}, x_{t}^{\Phi}\right.$ is a vector of explanatory variables, $w_{t}^{\mathbb{\Phi}=}\left(1, y_{t-1}, \ldots, y_{t-p}\right) \mathbb{\Phi}$, and $x_{t}=\left(x_{1 t}, \ldots, x_{k t}\right) \mathbb{\Phi}^{\mathbb{C}}$ which is a vector of exogenous variables. Furthermore, $\varphi$ and $\theta$ are parameter vectors and $u_{t}: \operatorname{iid}\left(0, s^{2}\right)$. Transition function $G\left(g, c, s_{t}\right)$ is a bounded function of the continuous transition variable $s_{t}, \gamma$ is the slope parameter and $c$ is a vector of location parameters. In this study we assume that the transition function is a general logistic function ${ }^{5}$ :

$G\left(g, c, s_{t}\right)=\left(1+\exp \left\{1-g \underset{\bigcup_{k}}{K}\left(s_{t}-c_{k}\right)\right\}\right)^{-1}, g>0$

where $\gamma>0$ is an identifying restriction. Equations (8) and (9) jointly define the logistic STR (LSTR) model. The most common choices for $K$ are $K=1$ (LSTR1 Model) and $K=2$ (LSTR2 model). When $\gamma=0$, the transition function $G\left(g, c, s_{t}\right)^{\circ} 1 / 2$, and the STR model nests the linear model. 
When $\gamma \rightarrow \infty$, the LSTR1 model approaches the switching regression model with two regimes (see van Dijk et al 2002).

In testing for linearity we follow Terasvirta (1998) and run the auxiliary regression:

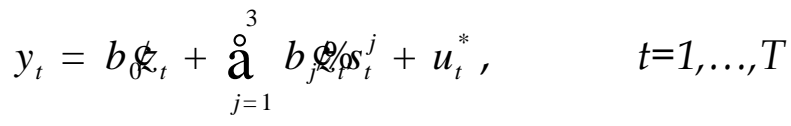

where the transition variable $s_{t}$ is an element in $z_{t}=\left(1, \tilde{z}_{t}^{\prime}\right)$, where $\tilde{z}_{t}^{\prime}$ is an $(m \times 1)$ vector.

The null hypothesis is $H_{0}: b_{1}=b_{2}=b_{3}=0$ and has an approximate $F$ distribution with $3 m$ and T-4m-1 degrees of freedom under the null. The choice between LSTR1 and LSTR2 can be based on regression (10). The following short test sequence is employed:

1. Test the null hypothesis $H_{04}: \beta_{3}=0$ in (10).

2. Test $H_{03}: \beta_{2}=0 \mid \beta_{3}=0$

3. Test $H_{04}: \beta_{1}=0 \mid \beta_{2}=\beta_{3}=0$

The results reject linearity in all cases with the exception of South Africa (with trend) (see Table $5 \mathrm{~A}$ where $F_{4}$ is for $\mathrm{H}_{04}$ etc). 
Table 5A: Smooth Transition Regression Models

\begin{tabular}{|c|c|c|c|c|c|c|}
\hline \multicolumn{7}{|c|}{ TESTING LINEARITY AGAINST STR } \\
\hline \multicolumn{2}{|c|}{ transition variable } & $\mathrm{F}$ & $\mathrm{F} 4$ & F3 & $\mathrm{F} 2$ & $\begin{array}{c}\text { suggested } \\
\text { model }\end{array}$ \\
\hline \multirow[t]{3}{*}{ Morocco } & $(\mathrm{t}-1)$ & 1.49E-07 & 8.82E-06 & 1.59E-03 & 4.35E-02 & LSTR1 \\
\hline & $(\mathrm{t}-2)$ & $1.44 \mathrm{E}-02$ & 3.90E-01 & 1.09E-02 & 8.36E-02 & LSTR2 \\
\hline & trend & 1.17E-02 & 2.45E-02 & $1.43 \mathrm{E}-01$ & 9.39E-02 & LSTR1 \\
\hline \multirow[t]{3}{*}{ Zimbabwe } & $(\mathrm{t}-1)$ & 1.49E-07 & 8.82E-06 & $1.59 \mathrm{E}-03$ & 4.35E-02 & LSTR1 \\
\hline & $(\mathrm{t}-2)$ & 1.44E-02 & 3.90E-01 & 1.09E-02 & 8.36E-02 & LSTR2 \\
\hline & trend & 1.17E-02 & 2.45E-02 & $1.43 \mathrm{E}-01$ & 9.39E-02 & LSTR1 \\
\hline \multirow[t]{3}{*}{ Tunisia } & $(t-1)$ & 1.16E-11 & 4.04E-02 & 4.540E-05 & $1.179 \mathrm{E}-08$ & LSTR1 \\
\hline & $(\mathrm{t}-2)$ & 2.29E-17 & $6.00 \mathrm{E}-01$ & $1.329 \mathrm{E}-11$ & 2.636E-09 & LSTR2 \\
\hline & trend & 3.13E-04 & 6.67E-02 & $9.726 \mathrm{E}-05$ & 4.718E-01 & LSTR2 \\
\hline \multirow[t]{3}{*}{ Kenya } & $(t-1)$ & $8.10 \mathrm{E}-67$ & $9.11 \mathrm{E}-12$ & $7.54 \mathrm{E}-17$ & $1.75 \mathrm{E}-43$ & LSTR1 \\
\hline & $(t-2)$ & $3.41 \mathrm{E}-66$ & 2.90E-16 & $1.85 \mathrm{E}-19$ & $9.42 \mathrm{E}-36$ & LSTR1 \\
\hline & trend & $1.65 \mathrm{E}-14$ & $1.20 \mathrm{E}-11$ & $7.45 \mathrm{E}-03$ & 2.67E-04 & LSTR1 \\
\hline \multirow[t]{3}{*}{ Nigeria } & $(t-1)$ & 3.63E-04 & $1.04 \mathrm{E}-02$ & $1.86 \mathrm{E}-02$ & 2.06E-02 & LSTR1 \\
\hline & $(\mathrm{t}-2)$ & 4.49E-04 & $2.59 \mathrm{E}-02$ & $1.74 \mathrm{E}-03$ & 1.14E-01 & LSTR2 \\
\hline & trend & 3.13E-03 & 2.64E-01 & 8.70E-02 & $2.50 \mathrm{E}-03$ & LSTR1 \\
\hline \multirow[t]{3}{*}{ S. Africa } & $(t-1)$ & 3.49E-03 & 9.37E-03 & 3.64E-02 & 1.77E-01 & LSTR1 \\
\hline & $(\mathrm{t}-2)$ & 1.20E-04 & 3.79E-05 & $6.29 \mathrm{E}-02$ & $4.68 \mathrm{E}-01$ & LSTR1 \\
\hline & trend & $1.75 \mathrm{E}-01$ & 5.75E-01 & $2.90 \mathrm{E}-01$ & 7.14E-02 & Linear \\
\hline \multirow[t]{3}{*}{ Egypt } & $(t-1)$ & 2.38E-05 & 3.79E-02 & $1.54 \mathrm{E}-05$ & 2.97E-01 & LSTR2 \\
\hline & $(t-2)$ & 1.45E-02 & 7.20E-02 & 8.18E-03 & 6.11E-01 & LSTR2 \\
\hline & trend & 4.45E-03 & 7.93E-03 & $1.70 \mathrm{E}-02$ & $6.06 \mathrm{E}-01$ & LSTR1 \\
\hline
\end{tabular}

We then proceed with estimating the suggested STR model in each case (results are available upon request) and finally test the residuals of the STR for ARCH effects. The results (see Table 5B) ${ }^{6}$ show that a GARCH structure exists and as a result the STR-type of non-linearity can not approximate the data generating process of the African stock market data ${ }^{7}$.

Table 5 B: ARCH LM test for the Residuals of the Best STR regression

\begin{tabular}{lccccccc}
\hline \hline & \multicolumn{7}{c}{ ARCH LM test $p$-values (F) } \\
& Morocco & Zimbabwe & Tunisia & Kenya & Nigeria & S. Africa & Egypt \\
1 lag & 0.000 & 0.000 & 0.000 & 0.000 & 0.000 & 0.001 & 0.000 \\
2 lags & 0.000 & 0.000 & 0.000 & 0.000 & 0.000 & 0.001 & 0.000 \\
3 lags & 0.000 & 0.000 & 0.000 & 0.000 & 0.000 & 0.000 & 0.000 \\
\hline \hline
\end{tabular}




\subsection{GARCH Models}

Estimates of GARCH, GARCH-M and E-GARCH-M models are presented in tables 9A and 9B. Even though the non-linearity tests provide evidence for second moment time dependencies, they cannot be used for the empirically observed phenomenon of asymmetric volatility and therefore the test suggested by Engle and Ng (1993) is also employed. These are based on the news impact curve implied by the GARCH model. The underlying idea is that if the volatility process is correctly specified, then the squared standardized residuals should not be predictable on the basis of observed variables. These tests are $(a)$ the sign bias test, $(b)$ the negative size bias test, $(c)$ the positive size bias test, and (d) the joint test. (Table 6).

The joint test on the residuals from the GARCH model rejects the null of symmetry for Morocco, Kenya, Tunisia, and Zimbabwe. However, some of the individual tests indicate rejection of the null but the overall test does not for the case of South Africa, Nigeria and Egypt. These contradictions are somewhat surprising. However, as Engle and $\mathrm{Ng}$ (1993) argue, the joint test is more powerful than the individual tests. We therefore do not estimate asymmetric GARCH for Egypt, Nigeria and South Africa. 
Table 6: Test for Asymmetry

\begin{tabular}{|c|c|c|c|c|c|c|c|}
\hline & Egypt & Morocco & Nigeria & Kenya & S.Africa & Tunisia & Zimbabwe \\
\hline $\begin{array}{c}\text { Sign Bias } \\
(t \text {-test })\end{array}$ & $\begin{array}{l}0.0608 \\
(0.624)\end{array}$ & $\begin{array}{l}0.1329 \\
(0.782)\end{array}$ & $\begin{array}{l}0.0158 \\
(0.183) \\
\end{array}$ & $\begin{array}{c}0.4836^{* *} \\
(2.107)\end{array}$ & $\begin{array}{l}0.1304 \\
(1.594)\end{array}$ & $\begin{array}{l}0.275^{*} \\
(1.686)\end{array}$ & $\begin{array}{l}-0.1453 \\
(-0.938) \\
\end{array}$ \\
\hline $\begin{array}{c}\text { Positive } \\
\text { Size } \\
\text { bias }(t \text {-test })\end{array}$ & $\begin{array}{c}0.1608^{* *} \\
(2.103)\end{array}$ & $\begin{array}{l}0.0398 \\
(0.258)\end{array}$ & $\begin{array}{c}0.1531^{* *} \\
(2.227)\end{array}$ & $\begin{array}{l}-0.0835 \\
(-0.462)\end{array}$ & $\begin{array}{l}-0.185^{\star *} \\
(-2.576)\end{array}$ & $\begin{array}{l}-0.0178 \\
(-1.456)\end{array}$ & $\begin{array}{c}-0.0010 \\
(-0.0083)\end{array}$ \\
\hline $\begin{array}{c}\text { Negative } \\
\text { Size Bias } \\
\text { (t-test) }\end{array}$ & $\begin{array}{c}-0.1104 \\
(-1.35)\end{array}$ & $\begin{array}{l}0.0314 \\
(0.247)\end{array}$ & $\begin{array}{l}-0.0103 \\
(-0.139)\end{array}$ & $\begin{array}{l}-0.3134 \\
(-1.625)\end{array}$ & $\begin{array}{l}-0.149^{* *} \\
(-2.316)\end{array}$ & $\begin{array}{c}0.0285 \\
(0.1977)\end{array}$ & $\begin{array}{l}-0.0196 \\
(-0.158)\end{array}$ \\
\hline $\begin{array}{c}\text { Joint test, } \\
\text { F-test, } \\
\chi^{2}\end{array}$ & $\begin{array}{l}11.456 \\
{[0.009]}\end{array}$ & $\begin{array}{c}2.203 \\
{[0.531]}\end{array}$ & $\begin{array}{l}9.1875 \\
{[0.003]}\end{array}$ & $\begin{array}{c}5.394 \\
{[0.145]}\end{array}$ & $\begin{array}{c}9.565 \\
{[0.003]}\end{array}$ & $\begin{array}{c}5.605 \\
{[0.133]}\end{array}$ & $\begin{array}{c}1.791 \\
{[0.616]}\end{array}$ \\
\hline \multicolumn{8}{|c|}{$\begin{array}{l}\text { Notes: } p \text {-values are shown in [ ] and } t \text {-statistics in () parenthesis.*, } \\
\text { and } 1 \% \text { respectively. } \\
\{a\} \text { SB: } z_{t}^{2}=\alpha+b S_{t}^{-}+e_{t} \\
\{b\} \text { PSB: } z_{t}^{2}=\alpha+b S_{t}^{-} \varepsilon_{t-1}+e_{t} \\
\{c\} \text { NSB: } z_{t}^{2}=\alpha+b\left(1-S_{t}^{-}\right) \varepsilon_{t-1}+e_{t} \\
\{d\} \text { Joint test: } z_{t}^{2}=\alpha+b_{1} S_{t}^{-}+b_{2} S_{t}^{-} \varepsilon_{t-1}+b_{3}\left(1-S_{t}^{-}\right) \varepsilon_{t-1}+e_{t}\end{array}$} \\
\hline
\end{tabular}

\subsection{Relationship between Conditional Volatility and Market Efficiency.}

The student $t$-distribution was employed for the GARCH estimates of table 9 to allow for fatter tails (given the evidence from Table 2). The lagged returns are significant in all countries and across all models. These findings imply that past information is useful in predicting the future path of prices and trading strategies could be build to beat the market, evidence inconsistent with the EMH. However this argument neglects the joint hypothesis problem inherent in all empirical efficiency studies and strictly speaking, this cannot be interpreted as rejection of weak form efficiency. Time varying volatility models would be informative about weak form efficiency to the extent that conditional 
variances help in predicting future returns (see Millionis and Moschos, 2000). For weak form efficiency to be violated we expect an increase in conditional variance (and hence risk) to result in a decrease in expected returns (i.e. statistically significant and negative $\delta$ in equation 5). In table 9, this would have been the case if the estimated negative coefficient of the conditional variance in Egypt and Nigeria (GARCH-M) were statistically significant. Since it is insignificant in the two countries we cannot claim violation of weak form efficiency. Furthermore, Schwaiger (1995) showed that GARCH in stock returns can be seen as a result of rational and hence efficient equilibrium pricing.

The GARCH parameterization in table 9 is highly statistically significant in all cases; the $\beta$ coefficient in the conditional variance equation is considerably larger than $\alpha$ and the conditional variance generally shows a high degree of persistence (as measured by $\alpha+\beta$ ). The evidence from table 9 are in line with Brooks (2007) who also find high persistence in the conditional variance of stock returns in African countries. For instance, in Brooks (2007) APARCH model, $\alpha+\beta=0.904$ for Morocco whereas we find $\alpha+\beta=0.98$ for the EGARCH-M. This implies that shocks to the conditional variance will be highly protracted. For the volatility process to be weakly stationary the sum of $\alpha+\beta$ must be less than unity ${ }^{8}$ This is generally consistent with the estimates in table 9. We shall argue here that the presence of variance dynamic in the stock market returns in all the countries can be seen as the result of a rational equilibrium pricing, so that their presence do not indicate market inefficiency. 
It has been found empirically that emerging stock markets are more volatile than their developed counterparts (see Harvey, 1995). This brings to fore the question of whether investors in these markets are compensated for assuming higher levels of risk (see Engle et al, 1987). The risk premium parameter $\delta$ is significant in all the estimated models in Kenya, Tunisia and Zimbabwe but only in EGARCH-M in the case of Morocco. For these countries, higher risk proxied by the conditional variance will lead to higher returns.

A possible explanation for the existence of risk premium in the four countries could be attributed to the prevailing interest rates ${ }^{9}$. Additionally, the perceived risk (e.g. political risk and economic policy) of investing in Africa's nascent economies raises the risk premium. Finally, we could argue that low liquidity, which is generally a key feature of African stock markets plays a role in explaining the risk premiums because investors in general prefer to have their assets in forms that takes less time and money to realize. In Egypt, Nigeria and South Africa we do not detect any significant relationship between expected returns and conditional variance. These are quite surprising and contrary to predictions of most asset pricing models. However, these are not isolated case as risk premiums tend to disappear over time, (e.g. see Baillie and De Gennaro, 1990 and Nelson, 1991).

Our results indicate that different parameterisation of the conditional variance yields different volatility outcomes. However, consistent across the estimates is the finding that high volatility is observed in markets that are less regulated and have little foreign participation. We observe more volatility in 
our results for Zimbabwe owing to the fact that the market still has some restrictions on foreign participation (see table 1 for evidence). To confirm the latter, the risk premium also tends to be higher for Zimbabwe across all models compared to other countries. Empirical evidence from emerging markets indicates that high volatility makes investors more averse to holding stocks due to increased uncertainty. This in turn leads to investors demanding high risk premium in order to insure against increased uncertainty (see Jayasuriya, 2005).

Further from our results, we can conjecture that the more regulated and the more heavily capitalised the market, the less the volatility. Contrasting the key indicators in table 1 with the estimates of table 9, we find interesting similarities, as thinly traded and less regulated markets such as Kenya, Tunisia and Morocco, appear to be more volatile than heavily capitalised markets and more developed markets such as South Africa. Thus there is an obvious link between the state of development of the market and conditional volatility. This has been emphasized by Jayasuriya (2005) who notes that weaker regulatory systems in developing countries reduce efficiency of the markets signals and the processing of information which magnifies the problem of volatility.

Figures 1 to 3 provide the conditional variance graphs for the preferred (symmetric) volatility model in each market. Next we examine the question of asymmetry in volatility. The asymmetry term is only significant for Morocco (5\% level) and Kenya (1\% level). In these two markets, negative shock to the conditional variance tends to have more impact on volatility than positive shock of the same magnitude. This is typically observed in most developed 
markets where a fall in a firms stock causes the debt to equity ratio to rise sharply. Figures 4 to 7 present the estimated news impact curves of the preferred EGARCH model.

\subsection{Diagnostics}

The Ljung-Box statistics on the standardized residuals and the standardized squared residuals of the GARCH, GARCH-M and EGARCH-M models in Table 9 find that there is no evidence of serial correlations (see also the discussion in Lundbergh and Terasvirta 2002). Furthermore, there is no evidence of conditional heteroscedasticity in the data. This implies that the fitted volatility models are adequate. As a further check, the standardized residuals from the GARCH models were used to calculate a battery of tests (summarised in table 7, see table 10 and 11 in the appendix for the details). 
Table 7: Summary of Results on Standardized Residuals

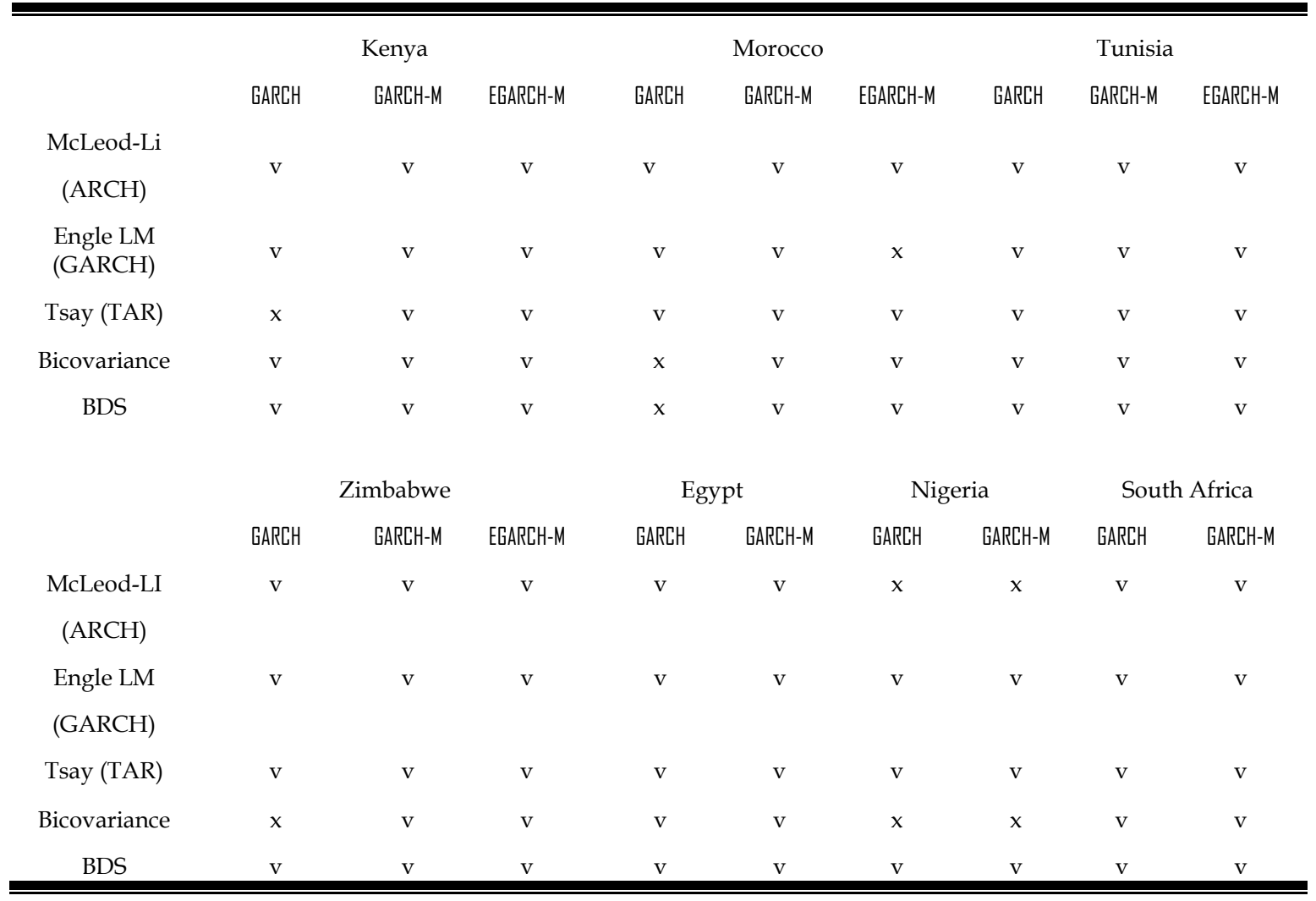

Note: $x$ denotes rejection of iid and $v$ is non-rejection at the $5 \%$ level. Readers should refer to tables 9 and 10 at the appendix for the details.

The vast majority of the calculated $p$-values on the standardized residuals of all equations cannot reject the null of iid. However the GARCH models in Morocco, Nigeria and Tunisia display contradictory results. In Nigeria, McLeod-Li and Bicovariance tests reject iid while the BDS and Engle LM do not. The BDS is more powerful (see Brock et al 1991 and Patterson and Ashley $2000)^{10}$. This is particularly valid for Nigeria since the computed information criteria selects GARCH-M as the best model. However, Morocco presents a more complicated scenario because only the Engle LM test rules out ARCH and Tsay rules out threshold effects. The BDS suggest there might still be possible structure in the GARCH standardized residuals. The same can be said for the 
GARCH model in Tunisia. With the exception of a few significant $p$-values, the overall results from all the models indicate that there is no remaining structure in the data.

To summarise the preferred model in each case was: Kenya: EGARCHM, Morocco: EGARCH-M, Tunisia: EGARCH-M, Zimbabwe: EGARCH-M, Egypt: GARCH, Nigeria: GARCH-M and South Africa GARCH.

\section{CONCLUSIONS}

This paper examined stock return dynamics and the implication of conditional volatility models in daily index returns for seven African countries (Egypt, Kenya, Morocco, Nigeria, South Africa, Tunisia and Zimbabwe). Random walk and smooth transition models were estimated and a battery of tests was employed in all cases. GARCH, GARCH-M and EGARCH-M were fitted to model the conditional variance.

The random walk model was rejected in all cases. It was found that the empirical stylized facts of volatility clustering, leptokurtosis and leverage effects are present in the African stock index returns. We showed that in Tunisia, Kenya and Morocco, investors are appropriately rewarded with higher returns for assuming greater risks. Also in Morocco and Kenya, changes in stock prices tend to be negatively related to changes in volatility. However, evidence to reject weak form efficiency for these markets was not found. 


\section{NOTES:}

1. See the Economist, June 11, 1994: "Stalking Africa's Fledgling Stock Markets".

2. The South African financial system is the most developed in Sub-Saharan Africa (SSA). A number of reforms dubbed 'big bang' were introduced in the 1990s paving way for the growth of the Johannesburg Securities Exchange (JSE). The JSE now uses up to date technology for trading based on the London Stock Exchange Electronic Trading Service (SETS). This allows both exchanges to leverage existing client relationships and promote remote access to cross boarder trade in most liquid securities. Derivative instruments have traded in South African financial markets since the late 1980s. Table 1 indicates the dominance of the JSE on the continent. In 2004, the market capitalisation was nearly \$500billion, compared with 1.9 billion in Zimbabwe, 14.5 billion in Nigeria. By the end of 2005, the JSE had market capitalization of \$566 billion, accounting for $94 \%$ of Sub-Saharan Africa's total and is more than 14 times larger than the all of the other markets combined. At the end of 2005 the JSE was ranked $16^{\text {th }}$ largest exchange in the world and its institutional characteristics are at par with leading emerging markets, such as Brazil, China and India.

A typical feature of all the markets considered in our sample is low liquidity. As Table 1 indicates, annual turnover ratio in African markets ranges from $8.2 \%$ in Kenya to $47.1 \%$ in South Africa in 2004. This contrasts with $115.5 \%$ and $113.3 \%$ in China and India respectively. Further African stock markets are small in comparison with their national economies as shown by the ratio of market capitalisation to GDP in column 5. Thus ranked in terms of capitalisation and turn over, African markets (outside South Africa) are minute. However, ranked in terms of important valuation parameters such as dividend yields (see column 7), earning price ratios and book value ratios, they are as comparable as their counterparts elsewhere. With the exception of Zimbabwe where a few restrictions remain, all African markets are opened to foreign investors. These institutional characteristics are crucial for understanding the evolution of stock returns in these countries and would thus inform the empirical analysis that follow.

3. The sample for Zimbabwe ends in 2001, short before the onset of the current economic crisis (numerous outliers appear after 2001 in this particular series).

4. It must however be emphasized that rejection of the random walk does not imply rejection of weak form efficiency in these markets. This is because a test of the random walk hypothesis is a joint test of both weak form efficiency and constancy of expected returns. To this end, a random walk with drift would be compatible with weak form efficiency because the drift will be positive and insignificant if investors expect a positive return. A random walk with drift was also considered but did not provide any qualitative different results.

5. For our claim of non-linearity in the data generation process to be valid, we need to employ all the possible linear models. In the present context we also employed a simple AR $(p)$ and a STAR model and tests of the residuals rejected the iid hypothesis (Results available on request).

6. The logistic function was also considered but the results of Table $5 \mathrm{~B}$ were not different.

7. Another type of nonlinearity is the STR-GARCH originally developed in Lundbergh and Terasvirta (1998). In this study we also considered the quadratic approximation employed by De Grauwe and Garibaldi (2001) but found this not to be superior to the GARCH models estimated in section.

8. For Zimbabwe we have $\alpha+\beta=0.95, \alpha+\beta=0.85$ and $\alpha+\beta=0.94$ for the GARCH, GARCH-M and EGARCH-M respectively. The GARCH and GARCH-M for Kenya are $\alpha+\beta=0.93$ and $\alpha+\beta=0.86$ respectively. However some of the estimates show Fractionally Integrated GARCH (FIGARCH) process see Bailie et al (1994). However due to the nature of this paper, such features of the data are left for further research.

9. Kenya has experienced rates and yields on treasury bills soaring to 80 and 90 percent up to the late 1990s. These have generally declined to between 20 to 30 percent on account of 
prudential financial management, and currently hovers around 10 percent. The North African economies have had manageable rates while Zimbabwe represents an extreme case, with current rates of about 500 percent (see Central bank of Zimbabwe www.rbz.co.zw).

10. However, two simulation studies by Brooks \& Heravi (1999) and Brooks \& Henry (2000) revealed that the BDS test can sometimes confuse different types of non-linear structure (such as threshold autoregressive and GARCH-type models) and has small power in detecting neglected asymmetries in conditional variance models. 


\section{REFERENCES}

Appiah-Kusi, J., and Menyah, K. 2003. Return Predictability in African Stock Markets. Review of Financial Economics 12, 247-270

Ashley, R.A. and Patterson D.M. 2006. Evaluating the effectiveness of state-switching time series models for US real output. Journal of Business and Economic Statistics 24, 266-277

Baillie, R.T., and DeGannaro, R.P. 1990. Stock Returns and Volatility. Journal of Financial and Quantitative Analysis 25,203-214.

Baillie, R.T., Bollerslev, T., and Mikkelsen, H.O.E. 1994. Fractionally Integrated Generalised Autoregressive Conditional Heteroscedasticity. Working Paper 9204, Michigan State University.

Bekaert, G., and Wu, G. 2000. Asymmetric Volatility and Risk in Equity Markets. Review of Financial Studies 13, 1-42

Black, F. 1976. Studies in Stock Price Volatility Changes: Proceedings of the 1976 Business Meeting of the Business and Economic Statistics Section, American Statistical Association, 177-181.

Bollerslev, T, Chou, R.C., and Kroner, K. 1992. ARCH Modelling in Finance: A Review of the Theory and Empirical Evidence. Journal of Econometrics 52, 5-59.

Bollerslev, T. 1986. Generalized Autoregressive Conditional Heteroscedasticity. Journal of Econometrics 31, 307-27.

Brock, W.A., Dechert, W. and Scheinkman, H and LeBaron, B. 1996. A test for independence based on the correlation dimension. Econometric Reviews 15, 197-235.

Brock, W.A., Hsieh, D.A., LeBaron, B. 1991. Nonlinear Dynamics, Chaos, and Instability, MIT Press, Cambridge, Massachusetts.

Brooks, C., and Heravi, S.M. 1999. The effect of (mis-specified) GARCH filters on the finite sample distribution of the BDS test. Computational Economics 13, 147-64

Brooks, C., Henry, O.T. 2000. Can Portmanteau Non-linearity tests serve as General miss-specification tests? Economics Letters 67, 245-51.

Brooks, R. 2007. Power ARCH modelling of the Volatility of Emerging Equity markets. Emerging Markets review 8, 124-133.

Caprio, G.J, and Demirguc-Kunt, A. 1998. The role of long-term finance: Theory and Evidence, World Bank Research Observer, 13 (2), 171-89.

Christie, A 1982. The Stochastic Behaviour of Common Stock Variances: Value, Leverage and Interest Rate Effects. Journal of Financial Economics 10, 407-432

Conrad, J., and Kaul, G. 1988.Time Variation in Expected Returns. Journal of Business $61,409-425$.

De Grauwe, P. and Grimaldi, M. 2001. Exchange rates, prices and money: a long-run perspective. Journal of International Money and Finance 20, 298-314.

Engel, R. 1982. Autoregressive Conditional Heteroscedasticity with Estimates of Variables of UK Inflation. Econometrica 50, 987-1008. 
Engel, R.F., and Ng, V.K. 1993. Measuring and Testing the Impact of News on Volatility. Journal of Finance 48, 1749-1778.

Engel, R.F., Lillien, D.M and Robins, R.P. 1987. Estimating Time Varying Risk Premia in the Term Structure: The ARCH-M Model. Econometrica 55(2), 391-407.

Fama, E.F, 1970. Efficient Capital Markets: A Review of Theory and Empirical Work. Journal of Finance. 25(2), 383-417.

Fama, E.F. 1965. The Behaviour of Stock Prices. Journal of Business 37(1), 34-105.

Fisher, L. 1966. Some New Stock Market Indices. Journal of Business 39,191-225.

French, K., Schwert, G.W., and Stambaugh, R 1987.Expected Stock Returns and Volatility", Journal of Financial Economics 19, 3-29.

Green, C.J., Kirkpatrick, C.H., and Murinde, V., 2005. Finance and Development: Surveys of Theory, Evidence and Policy. Edward Elgar Inc, UK.

Green, C.J., Maggioni, P., and Murinde, V., 2000. Regulatory Lessons for Emerging Markets from a Century of Evidence on Transactions Costs and Share Price Volatility in the London Stock Exchange. Journal of Banking and Finance 24, pp. 577-601.

Harvey, C.R. 1995. Predictable Risk and Return in Emerging Markets. Review of Financial Studies 8(3), 773-816.

Hinich, M.J 1996. Testing for Dependence in the Input to a Linear Time Series Model. Journal of Nonparametric Statistics 6,205-221.

Hinich, M.J., and Patterson, D.M. 1995. Detecting Epochs of Transient Dependence in White Noise, Mimeo, University of Texas at Austin.

Irving, J. 2005. Regional Integration of Stock Exchanges in Eastern and Southern Africa: Progress and Prospects, IMF Working paper WP/05/122.

Jayasuriya, S. 2005. Stock Market Liberalisation and volatility in the presence of favourable market characteristics and institutions. Emerging Markets Review 6, 170-191

Lo, A. W., and MacKinlay, A. C. 1988. Stock Prices Do Not Follow Random Walks: Evidence from a Simple Specification Test. The Review of Financial Studies 41-66.

Lim, K.P. 2007 Weak-form market efficiency and nonlinearity. Applied Economics Letters, 1-4, iFirst.

Lim, K.P., R. Brooks and J.H Kim. 2008. Financial crisis and stock market efficiency: Empirical evidence from Asian countries. International Review of Financial Analysis 17 (3), 571-591.

Lundbergh, S. and Terasvirta, T. 1998.Modelling economic high frequency time series with STAR GARCH models. Stockholm School of Economics Working Paper No. 291.

Lundbergh, S. and Terasvirta, T. 2002. Evaluating GARCH models. Journal of Econometrics. 110, 417-435

Magnusson, M.A., and Wydick, B. 2000. How efficient are Africa's Emerging Stock Markets? Journal of Development Studies 38(4). 
Mandelbrot, B. 1963.The variation of Certain Speculative Prices. Journal of Business 36, 394-419.

McLeod, A.I. and Li., W.K. 1983.Diagnostic Checking ARMA Time Series Models Using Squared-Residual Autocorrelations. Journal of Time Series Analysis 4, 269-273.

Mecagni, M., and Sourial, S.M. 1999.The Egyptian Stock Market: Efficiency Tests and Volatility Effects. IMF Working Paper, WP/99/48.

Millionis, A.E., and Moschos, D. 2000.On the Validity of the Weak Form Efficient Markets Hypothesis Applied to the London Stock Exchange: Comment. Applied Economics Letters, 7,419-421.

Nelson, D.B., 1991.Conditional Heteroscedasticity in Asset Returns: A New Approach.Econometrica 59, 347-70.

Panagiotidis, T. 2005.Market Capitalization and efficiency. Applied Financial Economics, 15, 707-713.

Patterson, D.M. and Ashley, R.A. 2000. A Nonlinear Time Series Workshop, Kluwer Academic, London.

Scholes, M., and Williams, J. 1977.Estimating Betas from Non-Synchronous Data. Journal of Financial Economics 5,309-327.

Schwaiger, W.S.A. 1995.A note on GARCH predictable variances and stock market efficiency. Journal of Banking and Finance 19, 949-953.

Schwert, G.W. 1990.Stock Volatility and the Crash of '87".Review of Financial Studies, 3, 77-102.

Smith, G., and Jefferis, K. 2005. The Changing Efficiency of African Stock Markets. South African Journal of Economics 73 (1), 54-67.

Standard and Poor's .2005. Global Stock Market Fact book; McGraw-Hill, New York.

Terasvirta, T. 1998. Modelling economic relationships with smooth transition regressions, in A. Ullah and D.E. Giles (eds), Handbook of Applied Economic Statistics, Dekker, New York, pp. 507-552.

Tsay, R.S. 1986. Nonlinearity tests for Time Series. Biometrica 73, 461-466.

van Dijk, D., Terasvirta, T. and Franses, P.H. 2002. Smooth Transition autoregressive models - A survey of recent developments. Econometric Reviews 21, 1-47.

Yartey, C.A., 2008. The Determinants of stock market development in Emerging Economies: Is South Africa any different, IMF Working Paper WP/08/32. 
APPENDIX

Table 8A: Tests on the Randomness of the RW Residuals

\begin{tabular}{|c|c|c|c|c|c|c|c|c|c|c|c|c|c|c|c|}
\hline & & \multicolumn{2}{|l|}{ Kenya } & \multicolumn{2}{|l|}{ Morocco } & \multicolumn{2}{|l|}{ Egypt } & \multicolumn{2}{|c|}{ South Africa } & \multicolumn{2}{|l|}{ Tunisia } & \multicolumn{2}{|l|}{ Nigeria } & \multicolumn{2}{|c|}{ Zimbabwe } \\
\hline & & Asymptotic & Boutstrap & Asymptotic & Boutstrap & Asymptotic & Boutstrap & Asymptotic & Boutstrap & Asymptotic & Boutstrap & Asymptotic & Boutstrap & Asymptotic & Boutstrap \\
\hline McLead-LI (20 lags) & & 0.000 & 0.000 & 0.019 & 0.019 & 0.000 & 0.013 & 0.000 & 0.000 & 0.000 & 0.03 & 0.000 & 0.001 & 0.000 & 0.004 \\
\hline McLead-LI( 24 lags) & & 0.000 & 0.000 & 0.000 & 0.000 & 0.000 & 0.016 & 0.000 & 0.000 & 0.000 & 0.033 & 0.000 & 0.000 & 0.000 & 0.004 \\
\hline \multicolumn{16}{|l|}{ Bicavariance } \\
\hline (17 lags) & & 0.000 & प.001 & 0.000 & 0.002 & 0.000 & 0.002 & 0.000 & 0.000 & 0.000 & 0.012 & 0.000 & 0.000 & 0.000 & 0.000 \\
\hline \multicolumn{16}{|l|}{ Engle LM } \\
\hline & 1 & 0.000 & 0.000 & 0.000 & 0.002 & 0.000 & 0.005 & 0.005 & 0.014 & 0.034 & 0.022 & 0.000 & 0.001 & 0.000 & 0.001 \\
\hline & 2 & 0.000 & 0.000 & 0.000 & 0.004 & 0.000 & 0.007 & प.००० & 0.005 & 0.000 & 0.004 & 0.000 & 0.002 & 0.000 & 0.002 \\
\hline & 3 & 0.000 & 0.000 & 0.000 & 0.005 & 0.000 & 0.01 & 0.000 & 0.007 & 0.000 & 0.007 & 0.000 & 0.001 & 0.000 & 0.002 \\
\hline & 4 & 0.000 & 0.000 & 0.000 & 0.008 & 0.000 & 0.011 & 0.000 & 0.003 & 0.000 & 0.008 & 0.000 & 0.001 & 0.000 & 0.002 \\
\hline & 5 & 0.000 & 0.000 & 0.000 & 0.011 & 0.000 & 0.016 & 0.000 & 0.003 & 0.000 & 0.008 & 0.000 & 1.0. & 0.000 & 0.002 \\
\hline Tsay & & 0.000 & 0.000 & 0.010 & 0.02 & 0.010 & 0.029 & 0.001 & 0.005 & 0.000 & 0.011 & 0.000 & 0.001 & 0.000 & 0.000 \\
\hline
\end{tabular}

Table 8B: BDS Test on RW Model

\begin{tabular}{|c|c|c|c|c|c|c|c|c|c|c|c|c|c|c|c|c|c|c|c|c|c|}
\hline \multirow{2}{*}{$\begin{array}{l}\text { Bootstrap } \\
\text { Dimension }\end{array}$} & \multicolumn{3}{|l|}{ Egypt } & \multicolumn{3}{|c|}{ Kenya } & \multicolumn{3}{|c|}{ Morocco } & \multicolumn{3}{|c|}{ Nigeria } & \multicolumn{3}{|c|}{ South Africa } & \multicolumn{2}{|c|}{ Tunisia } & \multicolumn{4}{|c|}{ Zimbabwe } \\
\hline & $\mathrm{EPS}=.5$ & $E P S=1$ & $E P S=2$ & $\mathrm{EPS}=.5$ & $E P S=1$ & $E P S=2$ & $E P S=.5$ & $E P S=1$ & $E P S=2$ & $\mathrm{EPS}=.5$ & $E P S=1$ & $E P S=2$ & $\mathrm{EPS}=.5$ & $E P S=1$ & $E P S=2$ & $\mathrm{EPS}=.5$ & $E P S=1$ & $E P S=2$ & $\mathrm{EPS}=.5$ & $E P S=1$ & $E P S=2$ \\
\hline 2 & 0.000 & 0.000 & 0.000 & 0.000 & 0.000 & 0.000 & 0.000 & 0.000 & 0.000 & 0.000 & 0.000 & 0.000 & 0.000 & 0.001 & 0.002 & 0.000 & 0.000 & 0.000 & 0.000 & 0.000 & 0.000 \\
\hline 3 & 0.000 & 0.000 & 0.000 & 0.000 & 0.000 & 0.000 & 0.000 & 0.000 & 0.000 & 0.000 & 0.000 & 0.000 & 0.000 & 0.000 & 0.000 & 0.000 & 0.000 & 0.000 & 0.000 & 0.000 & 0.000 \\
\hline 4 & 0.000 & 0.000 & 0.000 & 0.000 & 0.000 & 0.000 & 0.000 & 0.000 & 0.000 & 0.000 & 0.000 & 0.000 & 0.000 & 0.000 & 0.000 & 0.000 & 0.000 & 0.000 & 0.000 & 0.000 & 0.000 \\
\hline \multicolumn{22}{|l|}{ Asymptotic } \\
\hline 2 & 0.000 & 0.000 & 0.000 & 0.000 & 0.000 & 0.000 & 0.000 & 0.000 & 0.000 & 0.000 & 0.000 & 0.000 & 0.000 & 0.002 & 0.001 & 0.000 & 0.000 & 0.000 & 0.000 & 0.000 & 0.000 \\
\hline 3 & 0.000 & 0.000 & 0.000 & 0.000 & 0.000 & 0.000 & 0.000 & 0.000 & 0.000 & 0.000 & 0.000 & 0.000 & 0.000 & 0.000 & 0.000 & 0.000 & 0.000 & 0.000 & 0.000 & 0.000 & 0.000 \\
\hline 4 & 0.000 & 0.000 & 0.000 & 0.000 & 0.000 & 0.000 & 0.000 & 0.000 & 0.000 & 0.000 & 0.000 & 0.000 & 0.000 & 0.000 & 0.000 & 0.000 & 0.000 & 0.000 & 0.000 & 0.000 & 0.000 \\
\hline
\end{tabular}

Notes: only $p$-values are reported under the null hypothesis that the time series is a serially iid process. All calculations are done using the non-linear toolkit by Patterson and Ashley (2000). 
Table 9A: Estimated GARCH Models

\begin{tabular}{|c|c|c|c|c|c|c|c|c|c|}
\hline & Kenya & & & Morocco & & & Tunisia & & \\
\hline & $\mathrm{GARCH}$ & GARCH-M & EGARCH-M & $\mathrm{GARCH}$ & GARCH-M & EGARCH-M & $\mathrm{GARCH}$ & GARCH-M & EGARCH-M \\
\hline$\mu$ & $0.0004(1.2009)$ & 0.0004**(2.036) & -0.0009**(-2.18) & 0.000ा(0.975) & -0.000।|व2(-0.530) & -0.00023(-0.764) & -3.11E- - $55(-0.435)$ & -0.00006(-0.713) & -0.0006**(2.393) \\
\hline$\delta$ & & $0.28995 * *(2.1332)$ & $0.1135 * *(2.015)$ & & 0.01135**(2.015) & $5.523(0.702)$ & & |2.0102*(1.882) & $0.1627^{* *}(2.336)$ \\
\hline$\phi_{1}$ & $0.1864^{* * *}(4.014)$ & $0.2132^{* * *}(5.173)$ & $0.198^{* *}(7.782)$ & $0.273^{* * *}(8.37)$ & $0.2448^{* * *}$ (6.디) & $0.275^{* * *}(8.718)$ & $0.171^{* * *}(7.253)$ & $0.1805 * * *(6.077)$ & $0.1782^{* * *}(7.671)$ \\
\hline$\phi_{2}$ & $0.1915 * *(2.665)$ & $0.172^{* * *}(5.366)$ & & & 0.108|**(2.296) & & $\left.0.095\right|^{* * *}(4.0559)$ & $\left.0.096\right|^{* * *}(3.264)$ & 0.0923***(4.024) \\
\hline$\phi_{3}$ & $0.1135 * *(2.449)$ & $0.098 * *(2.846)$ & & & & & & & \\
\hline$\omega$ & I.IE- $05^{* * *}(3.054)$ & $0.000018 * * *(9.29)$ & $-1.312^{* * *}(-5.80)$ & 7.8E- $-\mathrm{DG}^{* * *}(3.4)$ & $\left.0.000006\right|^{* *}(2.798)$ & $-4.845 * * *(8.546)$ & 1.42E-D政**(4.634) & $0.00005^{* * *}(4.912)$ & $-1.1677^{* * *}(-5.964)$ \\
\hline$\alpha_{1}$ & $0.2728 * *(2.351)$ & $0.244^{* * *}(8.855)$ & $0.1432 * *(2.298)$ & $0.382^{* * *}(3.772)$ & $0.368745 * *(2.948)$ & $0.4189^{* * *}(10.392)$ & $\left.0.23\right|^{* * *}(6.2345)$ & $0.156^{* * *}(4.736)$ & $0.03482^{* * *}(9.066)$ \\
\hline$\alpha_{2}$ & & 0.1109**(2.95) & & & & $0.324^{* * *}(6 .|3|)$ & & & \\
\hline$\beta_{1}$ & $0.6535^{* * *}(6.865)$ & $0.5066^{* * *}(13.07)$ & $0.882^{* * *}(37.84)$ & $0.554^{* * *}(7.679)$ & $0.5467^{* * *}(5.2326)$ & $0.5765 * * *(10.79)$ & $\left.0.732\right|^{* * *}(23.69)$ & $0.843^{* * *}(45.18)$ & $0.916^{* * *}(54.72)$ \\
\hline$\gamma_{1}$ & & & $0.5722^{* * *}(3.585)$ & & & 0.078|**(2.815) & & & -0.0013(-0.055) \\
\hline AIC & -6.757 & -6.756 & -7.246 & -7.553 & -7.356 & -7.362 & -8.316 & -8.112 & -8.319 \\
\hline SBC & -6.727 & -6.723 & -7.213 & -7.552 & -7.326 & -7.322 & -8.295 & -8.094 & -8.296 \\
\hline \multirow[t]{2}{*}{ LBD(ID) } & 14.278[0.|61] & 12.274[0.198] & 0.0846[0.771] & 12.735[0.239] & 9.2133[0.512] & $11.178[0.344]$ & $11.868[0.294]$ & 12.884[0.230] & 10.897 \\
\hline & & & & & & & & & [0.366] \\
\hline LBDZ(II) & 1.661[0.998] & $0.8583[1.000]$ & $1.3146[0.999]$ & $3.157[0.977]$ & $3.8165[0.955]$ & 4.0415[0.945] & 2.166[0.995] & 2.368[0.99] & $1.8191[0.998]$ \\
\hline
\end{tabular}

$* * * * * *$ indicates significance at $1 \%, 5 \%$ and $10 \%$ levels respectively. AIC, SBC represent the Akaike and Schwarz criterion. LBQ is the Ljung-Box statistic. Test statistics are reported in ( ) while $p$-values are reported in [ ] beside the calculated coefficient 
Table 9B: Estimated GARCH Models

\begin{tabular}{|c|c|c|c|c|c|c|c|c|c|}
\hline & Zimbabwe & & & Egypt & & Nigeria & & South Africa & \\
\hline & GARCH & GARCH-M & EGARCH-M & GARCH & GARCH-M & GARCH & GARCH-M & GARCH & GARCH-M \\
\hline$\mu$ & $0.00087 *(1.895)$ & $0.0008^{* * *}(4.018)$ & 0.0007**(2.778) & 0.0037(1.399) & $0.00067(1.166)$ & $0.00014 *(1.859)$ & $0.00018^{* *}(2.869)$ & 0.0008**(2.899) & 0.0०083***(3.053) \\
\hline$\delta$ & & $4.498 * * *(3.273)$ & $\left.4.726\right|^{* *}(2.255)$ & & -0.6261(-0.397) & & -0.00007(-0.3833) & & 0.0117(0.0022) \\
\hline$\phi_{1}$ & $0.2291 * * *(4.355)$ & ०.20009***(6.103) & $\left.0.196\right|^{* * *}(7.0821)$ & $0.128 \mathrm{~b}^{* * *}(4.429)$ & $0.1169 * *(2.236)$ & $0.3335 * * *(15.117)$ & $0.345^{* * *}(15.791)$ & $0.1096^{* * *}(3.558)$ & $0.1072^{* * *}(3.639)$ \\
\hline$\phi_{2}$ & $0.1828^{* * *}(4.957)$ & $\left.0.160\right|^{* * *}(6.287)$ & $0.1114^{* * *}(4.543)$ & & & $0.1562 * * *(7.007)$ & $\left.0.154\right|^{* * *}(7 . \mid[\mid)$ & & \\
\hline$\phi_{3}$ & & $0.077^{* * *}(3.545)$ & & & & & & $-\left.0.06\right|^{* *}(-2.15)$ & \\
\hline$\omega$ & 4.56E- $-\square 5^{* * *}(4.99)$ & $0.000047^{* * *}(16.939)$ & $-1.6125^{* * *(6.291)}$ & 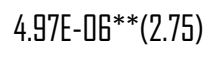 & $0.0000039 *(2.115)$ & $2.64 \mathrm{E}-\mathrm{07} 7^{* * *}(5.17)$ & $0.000034^{* * *}(6.175)$ & $2.15 E-0 \mathrm{~B} *(1.95)$ & $0.0000019^{* *}(2.675)$ \\
\hline$\alpha_{1}$ & 0.06238***(3.240) & 0.08505***(25.139) & $0.0959 * * *(3.464)$ & $0.2873^{* * *}(5.682)$ & $0.2071^{* * *}(5.069)$ & $0.0167^{* * *}(5.856)$ & $\left.0.234\right|^{* * *}(5.843)$ & $0.0738 * * *(4.73)$ & 0.0837***(3.975) \\
\hline$\beta_{1}$ & $0.8874^{* * *}(3.4539)$ & $0.7643^{* * *}(12.916)$ & $0.844^{* * *}(30.13)$ & $0.7739 * * *(30.17)$ & $0.8243^{* * *}(22.95)$ & $0.84972^{* * *}(4.097)$ & 0.2583**(2.301) & 0.901***(46.72) & $0.903^{* * *}(41.814)$ \\
\hline$\beta_{2}$ & & & & & & & $0.5283^{* * *}(5.548)$ & & \\
\hline$\gamma_{1}$ & & & $-0.0095(0.155)$ & & & & & & \\
\hline AIC & -5.852 & -5.855 & -6.207 & -5.792 & -5.605 & -7.393 & -7.401 & -6.317 & -6.309 \\
\hline SBC & -5.829 & -5.828 & -6.172 & -5.767 & -5.583 & -7.381 & -7.385 & -6.287 & -6.288 \\
\hline LBQ(ID) & $11.977[0.215]$ & 13.073[0.159] & $0.3394[0.841]$ & $11.406[0.327]$ & 10.603[0.304] & $6.931[0.436]$ & 6.8728[0.442] & 13.723[0.186] & 15.852[0.104] \\
\hline LBDZ(ID) & 12.787[0.236] & 14.861[0.137] & $11.375[0.329]$ & 4.227[0.936] & 6.7141[0.752] & 8.047[0.624] & 4.27[0.934] & 13.279[0.208] & 13.743[0.185] \\
\hline
\end{tabular}

$* * * * * *$ indicates significance at $1 \%, 5 \%$ and $10 \%$ levels respectively. AIC, SBC represent Akaike and Schwarz criterion. LBQ is the Ljung-Box statistic. Test statistics are reported in ( ) while $p$-values are reported in [ ] beside the calculated coefficients. 


\section{Table 10A: Non-Linearity Test on Standardized Residuals of GARCH Models}

\begin{tabular}{|c|c|c|c|c|c|c|c|c|c|c|c|c|c|c|c|c|c|c|c|}
\hline & & \multicolumn{6}{|l|}{ Kenya } & \multicolumn{6}{|l|}{ Morocco } & \multicolumn{6}{|l|}{ Tunisia } \\
\hline & & \multicolumn{2}{|c|}{ GARCH } & \multicolumn{2}{|c|}{ GARLH-M } & \multicolumn{2}{|c|}{ EGARLH-M } & \multicolumn{2}{|c|}{ GARCH } & \multicolumn{2}{|c|}{ GARLH-M } & \multicolumn{2}{|c|}{ EGARCH-M } & \multicolumn{2}{|c|}{ GARCH } & \multicolumn{2}{|c|}{ GARСH-M } & \multicolumn{2}{|c|}{ EGARCH-M } \\
\hline & & Asymptatic & Boutstrap & Asymptatic & Bontstrap & Asymptotic & Bootstrap & Asymptotic & Bootstrap & Asymptotic & Bontstrap & Asymptotic & Bootstrap & Asymptotic & Bontstrap & Asymptotic & Bootstrap & Asymptotic & Bootstrap \\
\hline McLend-LI(2Q lags) & & 0.640 & 0.598 & 0.627 & 0.606 & 0.400 & 0.379 & 0.051 & 0.057 & 0.811 & 0.796 & 0.236 & 0.214 & 0.276 & 0.242 & 0.883 & 0.869 & 0.813 & 0.565 \\
\hline McLend-LI(24 lags) & & 0.667 & 0.636 & 0.774 & 0.76 & 0.274 & 0.262 & 0.001 & 0.005 & 0.860 & 0.847 & 0.269 & 0.254 & 0.350 & 0.327 & 0.677 & 0.694 & 0.168 & 0.066 \\
\hline Bicavariance(17 lags) & & 0.347 & 0.313 & 0.740 & 0.675 & 0.935 & 0.836 & 0.029 & 0.076 & 0.274 & 0.242 & 0.634 & 0.55 & 0.362 & 0.343 & 0.230 & 0.211 & 0.555 & 0.556 \\
\hline \multicolumn{20}{|l|}{ Engle LM } \\
\hline & 1 & 0.492 & 0.507 & 0.947 & 0.943 & 0.619 & 0.815 & 1.000 & 0.991 & 0.439 & 0.44 & 0.022 & 0.025 & 0.849 & 0.867 & 0.105 & 0.101 & 0.812 & 0.805 \\
\hline & 2 & 0.773 & 0.786 & 0.424 & 0.434 & 0.192 & 0.182 & 0.868 & 0.862 & 0.741 & 0.745 & 0.071 & 0.066 & 0.364 & 0.345 & 0.185 & 0.196 & 0.653 & 0.66 \\
\hline & 3 & 0.885 & 0.894 & 0.623 & 0.616 & 0.247 & 0.235 & 0.636 & 0.608 & 0.698 & 0.694 & 0.064 & 0.052 & 0.479 & 0.478 & 0.217 & 0.237 & 0.105 & 0.09 \\
\hline & 4 & 0.648 & 0.652 & 0.679 & 0.669 & 0.209 & 0.192 & 0.788 & 0.781 & 0.480 & 0.471 & 0.121 & 0.112 & 0.491 & 0.457 & 0.345 & 0.353 & 0.136 & 0.124 \\
\hline & 5 & 0.777 & 0.777 & 0.764 & 0.744 & 0.315 & 0.295 & 0.882 & 0.882 & 0.490 & 0.477 & 0.083 & 0.069 & 0.618 & 0.585 & 0.457 & 0.472 & 0.033 & 0.034 \\
\hline Tsay & & 0.067 & 0.061 & 0.279 & 0.258 & 0.400 & 0.13 & 0.774 & 0.746 & 0.207 & 0.192 & 0.907 & 0.911 & 0.959 & 0.958 & 0.422 & 0.422 & 0.907 & 0.911 \\
\hline
\end{tabular}

\section{Table 10B: BDS Test on Standardized Residuals of GARCH Models}

\begin{tabular}{|c|c|c|c|c|c|c|c|c|c|c|c|c|c|c|c|c|c|c|c|c|c|c|c|c|c|c|c|}
\hline \multirow[b]{3}{*}{ Dimension } & \multicolumn{9}{|c|}{ Morocco } & \multicolumn{9}{|c|}{ Tunisia } & \multicolumn{9}{|c|}{ Kenya } \\
\hline & \multicolumn{3}{|l|}{ GARCH } & \multicolumn{3}{|c|}{ GARCH-M } & \multicolumn{3}{|c|}{ EGARCH-M } & \multicolumn{3}{|l|}{ GARCH } & \multicolumn{3}{|c|}{ GARCH-M } & \multicolumn{3}{|c|}{ EGARCH-M } & \multicolumn{3}{|l|}{ GARCH } & \multicolumn{3}{|c|}{ GARCH-M } & \multicolumn{3}{|l|}{ БАСН-M } \\
\hline & $\mathrm{EPS}=0.5$ & $E P S=1$ & $\mathrm{EPS}=2$ & $E P S=0.5$ & $\mathrm{EPS}=1$ & $\mathrm{EPS}=2$ & $E P S=0.5$ & $\mathrm{EPS}=1$ & $\mathrm{EPS}=2$ & $E P S=0.5$ & $E P S=1$ & $\mathrm{EPS}=2$ & $\mathrm{EPS}=0.5$ & $\mathrm{EPS}=1$ & $\mathrm{EPS}=2$ & $E P S=0.5$ & $E P S=1$ & $\mathrm{EPS}=2$ & $E P S=0.5$ & $E P S=1$ & $\mathrm{EPS}=2$ & $E P S=0.5$ & $E P S=1$ & $\mathrm{EPS}=2$ & $E P S=0.5$ & $\mathrm{EPS}=1$ & $\mathrm{EPS}=2$ \\
\hline \multicolumn{28}{|l|}{ Bontstrap } \\
\hline 2 & 0.000 & 0.107 & 0.741 & 0.931 & 0.749 & 0.853 & 0.983 & 0.97 & 0.969 & 0.031 & 0.061 & 0.51 & 0.374 & 0.415 & 0.775 & 0.285 & 0.236 & 0.843 & 0.632 & 0.501 & 0.495 & 0.386 & 0.515 & 0.581 & 0.053 & 0.024 & 0.135 \\
\hline 3 & 0.000 & 0.001 & 0.581 & 0.987 & 0.752 & 0.854 & 0.853 & 0.865 & 0.935 & 0.01 & 0.000 & 0.263 & 0.293 & 0.097 & 0.55 & 0.032 & 0.05 & 0.783 & 0.816 & 0.44 & 0.384 & 0.363 & 0.793 & 0.203 & 0.303 & 0.065 & 0.155 \\
\hline 4 & 0.000 & 0.000 & 0.423 & 0.996 & 0.797 & 0.767 & 0.623 & 0.624 & 0.902 & 0.014 & 0.000 & 0.173 & 0.304 & 0.083 & 0.548 & 0.039 & 0.065 & 0.793 & 0.93 & 0.367 & 0.388 & 0.424 & 0.791 & 0.137 & 0.564 & 0.12 & 0.131 \\
\hline \multicolumn{28}{|l|}{ Asymptotic } \\
\hline 2 & 0.000 & 0.101 & 0.745 & 0.937 & 0.771 & 0.871 & 0.98 & 0.994 & 0.971 & 0.026 & 0.071 & 0.548 & 0.388 & 0.429 & 0.577 & 0.298 & 0.245 & 0.829 & 0.681 & 0.521 & 0.522 & 0.249 & 0.53 & 0.151 & 0.059 & 0.023 & 0.126 \\
\hline 3 & 0.000 & 0.000 & 0.608 & 0.988 & 0.767 & 0.854 & 0.85 & 0.868 & 0.935 & 0.006 & 0.001 & 0.298 & 0.773 & 0.294 & 0.099 & 0.032 & 0.05 & 0.772 & 0.858 & 0.467 & 0.41 & 0.478 & 0.794 & 0.187 & 0.337 & 0.063 & 0.159 \\
\hline 4 & 0.000 & 0.000 & 0.441 & 0.993 & 0.798 & 0.79 & 0.848 & 0.656 & 0.908 & 0.006 & 0.000 & 0.183 & 0.319 & 0.076 & 0.572 & 0.033 & 0.061 & 0.776 & 0.941 & 0.401 & 0.408 & 0.772 & 0.798 & 0.224 & 0.603 & 0.118 & 0.137 \\
\hline
\end{tabular}


Table 11 A: Non-Linearity Test on Standardized Residuals of GARCH Models

\begin{tabular}{|c|c|c|c|c|c|c|c|c|c|c|c|c|c|c|c|c|c|c|c|}
\hline & & \multicolumn{6}{|c|}{ Zimbabwe } & \multicolumn{4}{|l|}{ Egypt } & \multicolumn{4}{|l|}{ Nigeria } & \multicolumn{4}{|c|}{ South Africa } \\
\hline & & \multicolumn{2}{|c|}{ GARLH } & \multicolumn{2}{|l|}{ GARCH-M } & \multicolumn{2}{|l|}{ EGARCH-M } & \multicolumn{2}{|l|}{ GARCH } & \multicolumn{2}{|l|}{ GARСH-M } & \multicolumn{2}{|l|}{ GARCH } & \multicolumn{2}{|l|}{ GARLH-M } & \multicolumn{2}{|l|}{ GARCH } & \multicolumn{2}{|l|}{ GARLH-M } \\
\hline & & Asymptotic & Bootstrap & Asymptotic & Bootstrap & Asymptotic & Bootstrap & Asymptotic & Bootstrap & Asymptatic & Bontstrap & Asymptotic & Boutstrap & Asymptotic & Bootstrap & Asymptatic & Bootstrap & Asymptatic & Bontstrap \\
\hline McLend-LI(20 lag & & 0.303 & 0.286 & 0.557 & 0.533 & 0.438 & 0.43 & 0.816 & 0.81 & 0.471 & 0.468 & 0.000 & 0.000 & 0.016 & 0.017 & 0.159 & 0.151 & 0.965 & 0.972 \\
\hline McLeod-LI(24 lag & & 0.382 & 0.353 & 0.666 & 0.65 & 0.232 & 0.236 & 0.827 & 0.82 & 0.557 & 0.555 & 0.000 & 0.000 & 0.005 & 0.009 & 0.241 & 0.234 & 0.563 & 0.54 \\
\hline $\begin{array}{l}\text { Bicavariance(17 } \\
\text { lags) }\end{array}$ & & 0.026 & 0.043 & 0.158 & 0.165 & 0.151 & 0.162 & 0.205 & 0.206 & 0.089 & 0.107 & प.००० & 0.001 & 0.042 & 0.065 & 0.522 & 0.49 & 0.220 & 0.246 \\
\hline \multicolumn{20}{|l|}{ Engle LM } \\
\hline & 1 & 0.370 & 0.361 & 0.216 & 0.199 & 0.642 & 0.626 & 0.420 & 0.418 & 0.483 & 0.496 & 0.052 & 0.054 & 0.062 & 0.065 & 0.692 & 0.686 & 0.519 & 0.523 \\
\hline & 2 & 0.624 & 0.603 & 0.450 & 0.426 & 0.741 & 0.749 & 0.688 & 0.703 & 0.296 & 0.271 & 0.070 & Q.व6 & 0.167 & 0.188 & 0.580 & 0.552 & 0.800 & 0.803 \\
\hline & 3 & 0.696 & 0.68 & 0.555 & 0.536 & 0.819 & 0.842 & 0.534 & 0.537 & 0.159 & 0.156 & 0.139 & 0.138 & 0.110 & 0.11 & 0.467 & 0.446 & 0.815 & 0.821 \\
\hline & 4 & 0.805 & 0.787 & 0.470 & 0.44 & 0.748 & 0.76 & 0.571 & 0.575 & 0.269 & 0.269 & 0.240 & 0.208 & 0.102 & 0.102 & 0.608 & 0.587 & 0.823 & 0.834 \\
\hline & 5 & 0.803 & 0.783 & 0.573 & 0.547 & 0.858 & 0.85 & 0.502 & 0.507 & 0.394 & 0.409 & 0.099 & 0.091 & 0.164 & 0.154 & 0.402 & 0.401 & 0.605 & 0.616 \\
\hline Tsay & & 0.136 & 0.128 & 0.351 & 0.33 & 0.153 & 0.159 & 0.903 & 0.905 & 0.209 & 0.198 & 0.172 & 0.174 & 0.253 & 0.28 & 0.465 & 0.473 & 0.405 & 0.389 \\
\hline
\end{tabular}

Table 11B: BDS Test on Standardized Residuals of GARCH Models

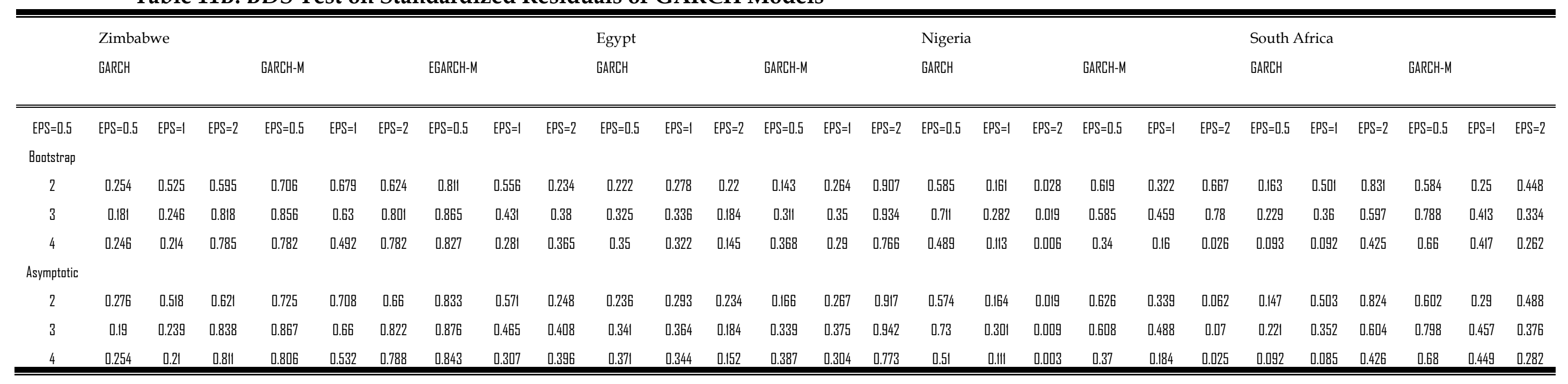

Notes: only $p$-values are reported under the null hypothesis that the time series is a serially iid process. 


\section{Conditional Variance Graphs}

Figures 1 to 3 presents the conditional variance for Egypt, Nigeria and South Africa. The conditional heteroscedasticity in the African indexes is clearly visible from these graphs. Note that there is a spike in the conditional variance around June 2006 in Egypt; between 2001 and 2002 in South Africa and end of 2000 in Nigeria. These coincide with periods of turbulence in those markets

\section{Figure 1: Conditional Variance of GARCH Model, Egypt}

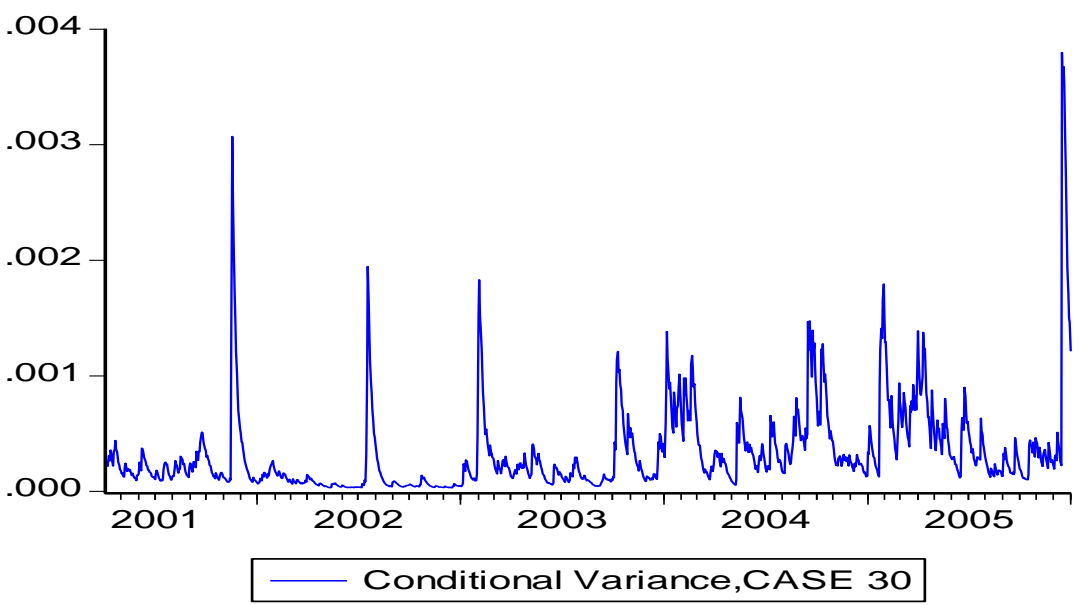

Figure 2: Conditional Variance of GARCH-M Model, Nigeria

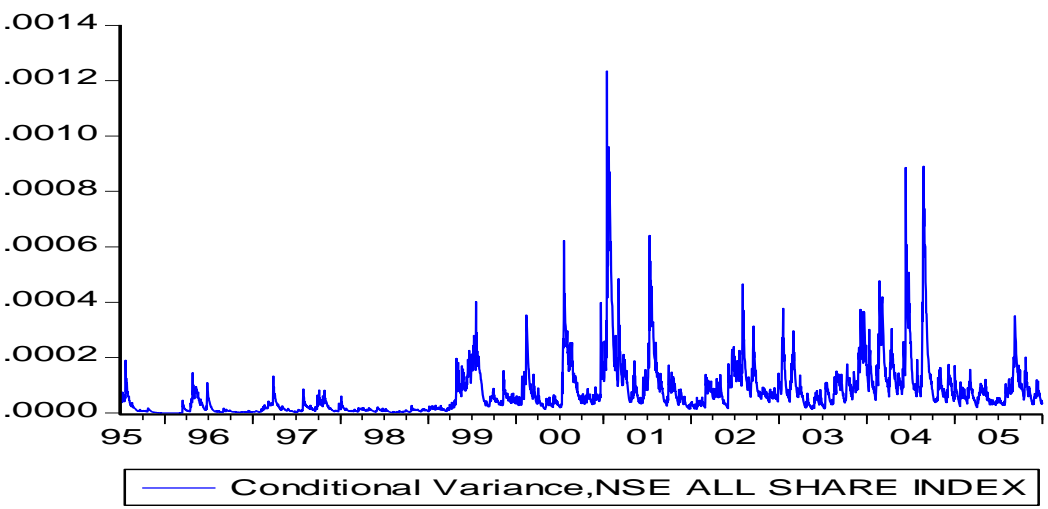

Figure 3: Conditional Variance of GARCH Model, South Africa

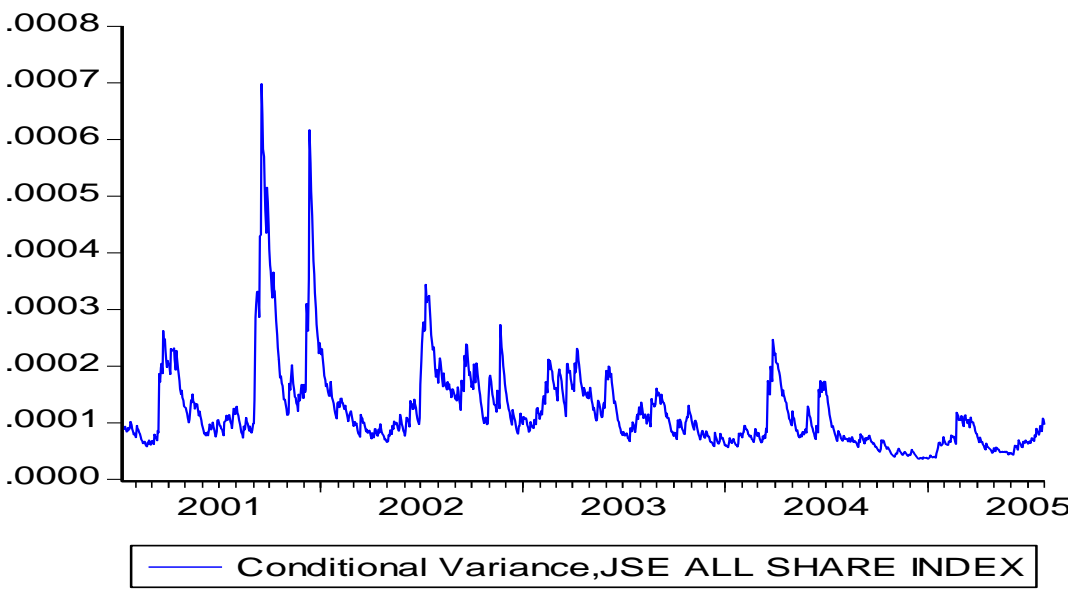




\section{News Impact Curves (NIC)}

The news impact curve plots conditional volatility against previous shocks of an estimated model. The curve is drawn by using the estimated conditional variance equation for the EGARCH-M, with its given coefficients, and with the lagged conditional variance set to the unconditional variance.

\section{Figure 4: NIC of EGARCH, Morocco}

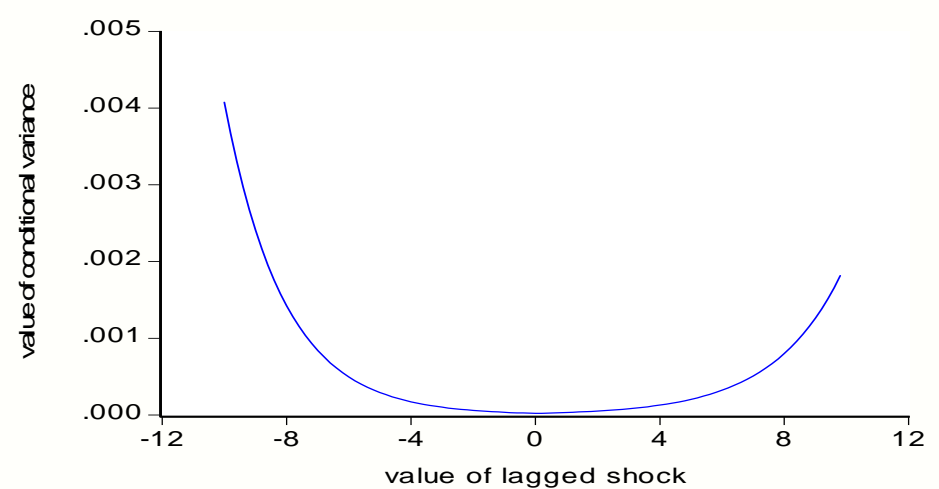

Figure 6: NIC of EGARCH, Kenya

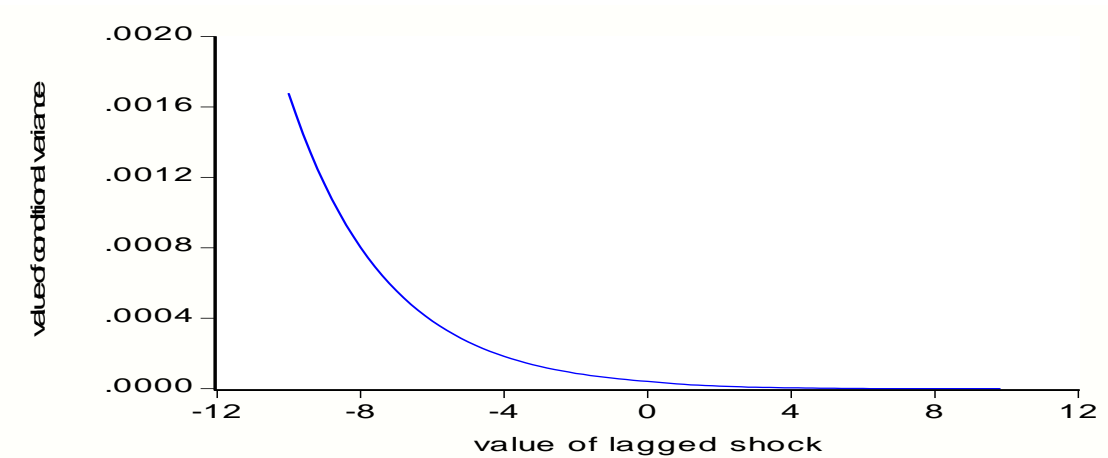

\section{Figure 5: NIC of EGARCH, Tunisia}

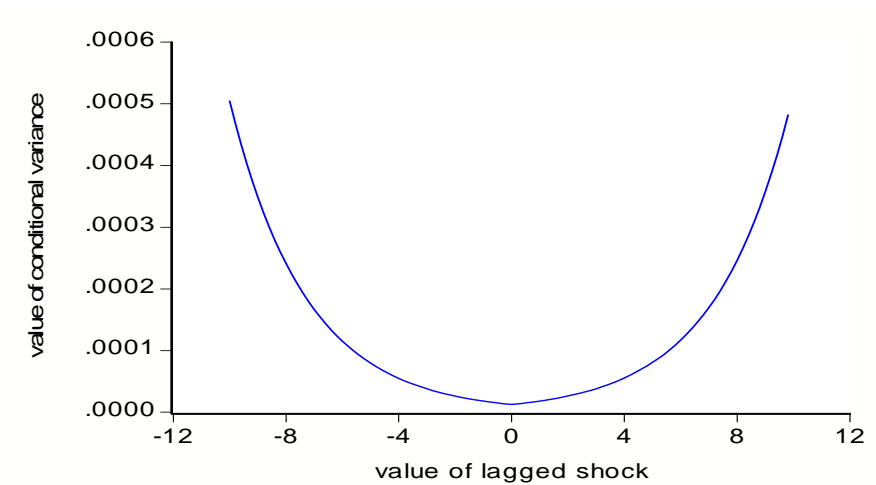

Figure 7: NIC of EGARCH, Zimbabwe

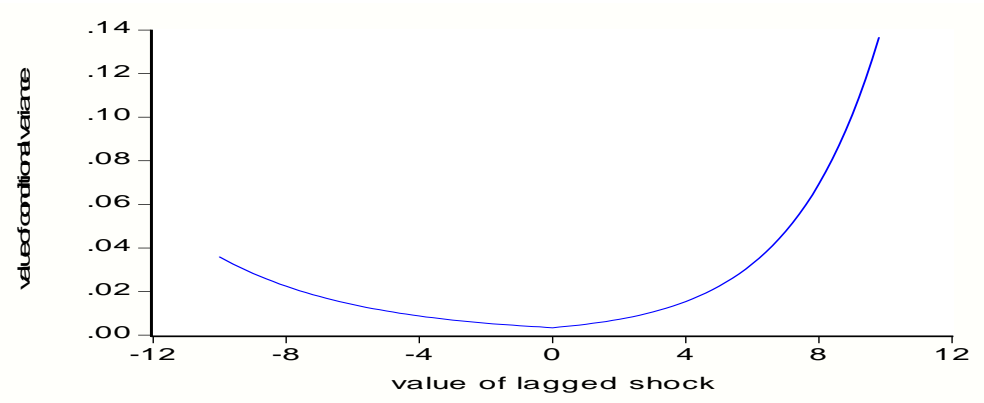

